\title{
LA TITULARIZACIÓN EN COLOMBIA: VEINTE AÑOS DE REGULACIÓN, 1993-2013
}

Constanza Blanco Barón*

L a titularización de activos, una importante fuente de financiación de proyectos de inversión, tiene numerosas ventajas para originadores e inversionistas, y es un vehículo para movilizar activos e impulsar el mercado.

Colombia hizo grandes avances en la regulación y la titularización de activos a comienzos de los años noventa, como muestran el alto número y la diversidad de procesos que tenían como subyacente documentos de crédito, proyectos inmobiliarios, infraestructura, cartera hipotecaria o proyectos agropecuarios (al final de la década) ${ }^{1}$. A comienzos del siglo la oferta pública de valores cobró impulso por el liderazgo de la titularización hipotecaria a través de sociedad titularizadora, como indican los datos del Registro Nacional de Valores y Emisores (RNVE) de la Superintendencia Financiera (SFC). No obstante, en los últimos años se observan altibajos en la titularización hipotecaria y un declive de la titularización no hipotecaria, que no recuperó los niveles de comienzos del siglo.

En el contexto colombiano no es común que el regulador evalúe el cumplimiento de los objetivos de las normas. El ejercicio que se

\footnotetext{
* Doctora en Sociología Jurídica. Coordinadora de la Maestría en Derecho con énfasis en Derecho Económico de la Universidad Externado de Colombia, Bogotá, Colombia [constanza.blanco@uexternado.edu.co]. Este artículo es parte de la línea de investigación sobre análisis económico del derecho financiero y bursátil del Grupo de Investigación en Derecho y Economía, proyecto Seguimiento al marco institucional del mercado de valores en Colombia. Fecha de recepción: 26 de junio de 2014, fecha de modificación: 5 de diciembre de 2014, fecha de aceptación: 29 de abril de 2015. Sugerencia de citación: Blanco B., C. "La titularización en Colombia: veinte años de regulación, 1993-2013", Revista de Economía Institucional 17, 32, 2015, pp. 259-294. DOI: 10.18601/01245996.v17n32.09

1 Blanco (2004) hace un balance de esta forma de financiación entre 1993 y 2003, en lo que atañe a los objetivos de política, a su comportamiento y su incidencia en el mercado de valores.
} 
hace en este artículo busca cubrir en parte ese vacío. Una pregunta que surge cuando se examinan procesos como la titularización es si el comportamiento de los agentes obedece a cambios institucionales, con objetivos concretos como el desarrollo de un sector específico, si los cambios del régimen normativo son consecuencia del comportamiento del mercado o responden a necesidades de la economía. Es claro que desde su inicio la titularización respondió a la introducción del marco para realizar estos procesos, pero no se habrían realizado de no existir solicitudes y una actitud propicia de la industria, así como la necesidad de financiar proyectos o de atenuar los efectos adversos de una crisis.

La teoría neoinstitucionalista puede ayudar a entender si el desempeño de los mercados es una respuesta a la regulación o una reacción a fallas del mercado. En el primer caso, las decisiones de los agentes estarían guiadas por las instituciones existentes (Bathelt, 2014), y se valoraría la expedición de un marco normativo que establezca responsabilidades, dé certeza al cumplimiento de los contratos, permita la conciliación de diferencias y, en suma, dé seguridad jurídica a sus actuaciones. En el segundo, ante las fallas del mercado se requiere que el Estado regule y supervise el comportamiento de los agentes, y que las autoridades del mercado ejerzan su capacidad para hacer cumplir las normas en sentido amplio y verificar el logro de sus objetivos (Baldwin et al., 2012).

Este artículo examina y evalúa los principales hechos o situaciones que han incidido en el comportamiento de la titularización en general y de la titularización hipotecaria en el mercado colombiano, asumiendo que esta es una innovación tecnológica, como la define Müller (2013), que tuvo impacto en el desarrollo del mercado de valores. Para Kaniadakis et al. (2014), la titularización hipotecaria es la mayor innovación en la financiación de hipotecas desde los años setenta. Como marco para el análisis se tomó la teoría del cambio institucional propuesta por North (1993), y desarrollada por Díaz (2005), Frunză y Stanciu (s. f.), Brownlow (2010) y López (2012). En el ámbito local no se encontraron artículos académicos sobre los últimos desarrollos de la titularización, la relación con la teoría del cambio institucional y su impacto en el desarrollo económico.

En la primera parte se presenta el marco teórico, asumiendo que la titularización de flujos de caja es una innovación ${ }^{2}$; en la segunda

${ }^{2}$ La titularización puede ser de flujos de caja (la que trata este artículo) o sintética. En la primera el originador (lender) vende sus créditos a los inversionistas a través de un vehículo de propósito especial (SVP en inglés) que emite los títulos; la sintética es la titularización de un grupo de documentos que representan obli- 
parte se describe el comportamiento de la oferta pública de títulos en procesos de titularización en sus diferentes modalidades de 1993 a 2002, año en que se creó la sociedad titularizadora, y desde 2002 hasta 2013; en la tercera parte se aplica el marco teórico al análisis de los resultados; en la cuarta parte se revisan algunos factores de oferta y de demanda que afectaron la titularización en general y la titularización hipotecaria en particular. Por último se presentan las conclusiones.

\section{MARCO TEÓRICO}

El marco teórico se presenta en dos secciones: en la primera se define la titularización de activos y se delimita el tema de investigación, y en la segunda se establece el ámbito de la teoría neoinstitucional que sirve de base para analizar las cifras de la titularización y examinar los factores que impulsaron su desarrollo.

\section{LA TITULARIZACIÓN DE FLUJOS DE CAJA (MOVILIZACIÓN DE ACTIVOS)}

La titularización de activos es "un proceso mediante el cual, una entidad originadora transfiere y aísla en un vehículo especial activos de su propiedad que tienen características de iliquidez o baja rotación, o flujos de caja futuros predecibles, con el objeto de iniciar nuevas operaciones o desarrollar proyectos"(Blanco, 2004); “el agrupamiento o empaquetamiento de activos financieros para ser transformados en títulos valores y vendidos o adquiridos por inversionistas" (según la Titularizadora Colombiana) ${ }^{3}$, o "el proceso por medio del cual se incorporan en múltiples documentos homogéneos, los derechos que poseen una o varias personas sobre uno o más bienes que tienen la capacidad de generar un flujo de caja, con el fin de lograr la circulación de dichos derechos" (Manrique, 1994).

La mayor parte de los trabajos recientes sobre titularización examina el comportamiento de los activos financieros sofisticados que provocaron la crisis de 2008, y la respuesta a la crisis de los organismos internacionales, las autoridades financieras y la industria. Entre los primeros, Kaniadakis (2014) explora las implicaciones de la estructura de información financiera en la financiación de hipotecas mediante titularización; Arias (2014) estudia la titularización como transferencia de obligaciones del originador y las características de la

gaciones, sin necesidad de que los subyacentes "cambien físicamente de manos", pues el emisor, en vez de adquirir el paquete de obligaciones, vende "protección" al originador mediante un CDS (credit default swap); ver Podolski (2012).

${ }^{3}$ Ver la página web de la Sociedad Titularizadora Colombiana, [www.titularizadora.com]. 
transacción en el derecho inglés, así como los problemas generados por su evolución en la crisis financiera de 2008; Uhde (2012) utiliza una sección transversal de 381 casos de titularización de caja y sintética entre 1997 y 2007 para buscar evidencia empírica del impacto negativo de los anuncios de titularización y del riesgo de crédito en el valor de los accionistas de los bancos originadores. Entre los autores que estudian la respuesta a la crisis, Marin (2012) examina la reforma de la Ley Dodd-Frank, y en particular el objetivo de mejorar el proceso de titularización hipotecaria; Podolski (2012) analiza la titularización sintética después de la crisis; y Kerle (2013) estudia la titularización de trade receivables como una de las grandes supervivientes de la crisis.

Según la acepción común, la tecnología son los conocimientos, habilidades y destrezas que dan lugar a productos o servicios que mejoran la calidad de vida. La titularización es una innovación en cuanto hay cambios cualitativos en los componentes de la tecnología, como propone Müller (2013): técnica, conocimiento, organización y producto. Para este autor, un cambio cuantitativo en uno de los componentes provoca cambios en los demás, y un cambio cualitativo en uno de los elementos que constituyen la tecnología da lugar a una innovación tecnológica (ibíd.).

La titularización incluye los procedimientos para emitir papeles en oferta pública a partir de subyacentes específicos, lo que requiere un conocimiento especializado de la estructuración de emisiones con este fin, y una organización en la que interactúan los agentes que realizan ciertas actividades en el mercado de valores para producir documentos o instrumentos financieros negociables. Es una innovación porque modificó la técnica o destreza para emitir valores, el conocimiento de la manera de desarrollar títulos más complejos que tienen respaldo en un subyacente, la organización para realizar este tipo de procesos desintermediados que financian a los originadores, y los productos resultantes, que no son títulos valores pero tienen sus características y prerrogativas.

En la estructuración de titularizaciones participan los siguientes agentes: el originador o dueño de los activos o derechos titularizables (subyacentes); el vehículo que adquiere el subyacente y que transforma esos activos en títulos valores con derechos de crédito, de participación o mixtos; el agente de manejo o fiduciaria para los subyacentes no hipotecarios y la sociedad titularizadora para la activos hipotecarios; el administrador del subyacente que da cuenta de la recuperación del flujo de caja que servirá para atender los pagos a los inversionistas; y otros participantes en la emisión en oferta pública: el estructurador del proceso, la calificadora, los colocadores (underwriters), el admi- 
nistrador de la emisión, el depósito de valores, el valorador del subyacente en el mercado primario, el sistema de negociación de títulos en el mercado secundario, los inversionistas y la SFC que autoriza la emisión, hace seguimiento y administra el RNVE, entre otras entidades relacionadas con la oferta pública ${ }^{4}$.

Una razón para que un agente inicie un proceso de titularización es que en su balance tenga activos de baja rotación o baja liquidez que generan flujos de caja predecibles, de los que no se quiere deshacer, pero cuyo plazo quiere acortar convirtiéndolos en efectivo a la vez que mejora el balance sacando el riesgo ${ }^{5}$. Para los bancos, es una posibilidad de obtener recursos de largo plazo y mejorar sus estados financieros (Blommestein, 2011). La decisión de titularizar activos implica valorar alternativas, entre ellas adquirir deuda mediante créditos bancarios o emisión de bonos o papeles comerciales, o aumentar el capital emitiendo acciones ${ }^{6}$. No obstante, el objetivo del proyecto puede ser anticipar flujos de caja, como sucede en proyectos inmobiliarios, recuperación de peajes para construir carreteras, adelanto de impuestos territoriales o de vigencias futuras correspondientes al presupuesto público, etc. A ello se suma la consideración de la carga tributaria en los diferentes pasos del proceso, como la que correspondería a los inversionistas en títulos por la rentabilidad correspondiente.

Desde el punto de vista del regulador del sistema financiero, la puesta en marcha de procesos como la titularización u otro producto novedoso es útil porque da al mercado nuevas opciones de financiación e inversión. Así, entre los objetivos de la regulación de estos procesos están la disposición de nueva oferta de títulos para el mercado de valores y la activación de un mercado secundario de hipotecas (Blanco, 2004).

\section{LA TEORÍA NEOINSTITUCIONALISTA}

La teoría microeconómica estudia algunas fallas del mercado, como las clásicas asimetrías de información, externalidades o bienes públicos (Pigou, 1946), o comportamientos anticompetitivos de los agentes y barreras de entrada o salida que afectan la formación de precios (Cuevas, 2001).

\footnotetext{
${ }^{4}$ La regulación define estos agentes, ver Decreto 2555 de 2010, art. 5.6.1.1.1 y ss. Sobre la titularización hipotecaria, ver art. 5.6.10.1.1 y ss.

${ }^{5}$ La razón para que un originador se deshaga de activos es sacar el riesgo de impago de su balance (Podolski, 2012). No obstante, para el regulador colombiano pudo ser tanto o más importante la movilización de activos poco líquidos o su conversión en efectivo, y así generar nuevos títulos para el mercado de valores.

${ }^{6}$ Para los bancos, la titularización sería menos costosa que la emisión de bonos $\mathrm{o}$ acciones.
} 
En el caso del sistema financiero, las fallas de mercado hacen necesaria la intervención del Estado mediante la expedición de un marco normativo que corrija las asimetrías de información, establezca responsabilidades, dé certeza del cumplimiento de los contratos, permita conciliar diferencias y dé seguridad jurídica a los agentes. Para lograr la eficiencia se requiere definir claramente los derechos de propiedad, cumplir los contratos y reducir los costos de transacción (Pinzón, 2010; Rubio, 2007). Pero tanto o más importante es la reacción de las autoridades a cambios en el mercado, especialmente en situaciones de crisis, cuando se necesita activar otros objetivos como la estabilidad sistémica.

Cuando el mercado se comporta en forma normal y en situaciones de crisis es importante que el Estado ponga de relieve su capacidad para hacer cumplir las normas. En sentido amplio, esta capacidad incluye varios aspectos, entre los que se cuenta la verificación del logro de los objetivos de la regulación, de modo que si una norma no obtiene resultados concretos se activen mecanismos para revisarla y ajustarla (Baldwin, 2012) ${ }^{7}$.

Para el buen desarrollo de las economías es necesario establecer marcos institucionales adecuados, bien sean reglas formales (normas jurídicas) o informales (normas sociales) que guíen la interacción y el comportamiento de los agentes (North, 1993). La teoría neoinstitucional plantea la necesidad de establecer incentivos adecuados para facilitar la adquisición de nuevos conocimientos, la innovación y la apropiación de nuevas tecnologías que tengan impacto en la manera de organizar los negocios y, por ende, en el desarrollo. Los cambios tecnológicos como 'motor' del desarrollo reducen los costos de transacción (Brownlow, 2010). Según North, esos cambios tecnológicos ocurren en forma incremental.

North plantea que las organizaciones son entidades ideadas para maximizar la riqueza o lograr otros objetivos, que son facilitados u obstaculizados por la estructura institucional de la sociedad (North, 1993), como las innovaciones tecnológicas y de incentivos que ayudan a modificar el "saber puro" y convertirlo en conocimiento aplicado. Así, las instituciones son determinantes de la actividad económica y de la creación de empresas, lo que impulsa el desarrollo de la economía.

La innovación no se limita a los procesos productivos o las formas de organización empresarial, en este artículo cobija la creación de formas de financiación no tradicionales. Así, a la estructuración de

${ }^{7}$ Detrás de estos planteamientos está la racionalidad formal-material, pues las normas jurídicas tienen objetivos concretos de atención de necesidades económicas (Morales, 2005). 
un proceso de titularización se le pueden aplicar los planteamientos sobre la innovación, en particular a la manera de financiar proyectos de inversión que requieren la anticipación de la caja sobre subyacentes tangibles o intangibles ${ }^{8}$.

Aquí cabe precisar que North define el cambio como "ajustes marginales al conjunto de reglas, normas y de su cumplimiento (sic) que constituyen el marco institucional" e inducen cambios en los precios relativos de los factores, en el poder para negociar contratos y en los gustos o preferencias. $\mathrm{El}$ proceso de cambio incluye entonces el agente, la fuente, el proceso y la vía del cambio (North, 1993; Díaz, 2005):

- Agente de cambio: un empresario que responde a los incentivos del marco institucional que tienen efectos en los precios relativos de los factores, en la información y la tecnología, y que toma decisiones dentro de las organizaciones según sus percepciones subjetivas. Este agente puede modificar la organización de los negocios decidiendo entre varias opciones.

- Fuente de cambio: los empresarios evalúan sus oportunidades según los cambios del entorno, y están atentos a las variaciones de precios relativos y los gustos o preferencias. En los cambios tiene un gran papel el aprendizaje de la experiencia o la adquisición de habilidades o conocimientos que llevan a "nuevos modelos mentales" para valorar las alternativas y llevar a cabo nuevos emprendimientos.

- Proceso de cambio: el cambio económico o político está condicionado por una variación de precios relativos que altere los contratos o acuerdos. Este proceso es incremental y ocurre en marcos institucionales que "consienten nuevas negociaciones y compromisos entre las partes" o nuevas maneras de hacer las cosas, y dan lugar a un escalamiento en el que los empresarios que se sienten favorecidos ayudan a elaborar normas superiores o a eliminar limitaciones informales (costumbres, formas de hacer las cosas).

- Via del cambio: los agentes aplican nuevos conocimientos o nueva tecnología para mejorar la eficiencia. Una vez se establece la vía del desarrollo sigue un curso que es reforzado por las externalidades de red, el aprendizaje de las organizaciones y la modelación subjetiva formada históricamente. Los “empresarios políticos” tienen más libertad y más responsabilidad para inducir cambios, según su percepción de los problemas.

${ }^{8}$ Según Taylor et al. (2009), las formas actuales de titularización son hipotecaria (Mortgaged Back Securities, MBS), no hipotecaria (Asset Back Securities, ABS) e IPS (Back Securities). La IPS se basa en un conjunto de derechos que producen un flujo de caja futuro no establecido, cuyo subyacente puede ser marcas, patentes $\mathrm{u}$ otros intangibles. 
Diversos autores analizan la idea de cambio institucional de North. Para Dolfsma (2008), este es causado por tensiones entre valores socio-culturales o entre instituciones, y el 'disparador' del cambio son las discrepancias entre agentes de instituciones concretas y los valores que representan. Por su parte, Heinrich (2013) lo estudia en un marco de teoría de juegos dinámica, donde se pueden obtener nuevas estrategias en forma gradual aplicando la teoría del cambio tecnológico de Veblen a situaciones particulares. Y Bathelt y Glücker (2014) examinan la interrelación entre cambio institucional y desarrollo económico precisando la definición de instituciones y considerando tres formas de cambio institucional: histéresis, cambio emergente y emprendimiento institucional.

Para Díaz (2005), el concepto de cambio institucional de North se basa en cinco premisas: primera, la clave del cambio es la interacción continua entre instituciones y organizaciones en contextos de competencia y escasez; segunda, los empresarios siempre buscan adquirir nuevos conocimientos y habilidades para sobrevivir en el mercado; tercera, el marco institucional determina el tipo de habilidades y conocimientos que se requieren para mejorar la rentabilidad; cuarta, la percepción de las opciones disponibles está determinada por la estructura mental de los agentes y, quinta, el cambio institucional ("abrumadoramente incremental") depende de las economías de escala, las economías complementarias y las redes externas que surjan del marco institucional ${ }^{9}$. Así, el factor esencial del cambio es el aprendizaje (la educación), y North abandona la idea de racionalidad perfecta para explorar el aprendizaje, el verdadero motor del cambio (ibíd.). Aunque los empresarios actúan siempre con criterios de eficiencia, no siguen una racionalidad instrumental weberiana, de medios a fines; su racionalidad es limitada, como argumenta Simon (Pinzón, 2010), y no obstante procuran reducir los costos de transacción y elevar la productividad de los recursos para aumentar la utilidad.

En el caso de los agentes o "empresarios" políticos, se esperaría que buscaran maximizar el interés público atendiendo a una racionalidad valorativa, en la que se pondera la posibilidad de lograr distintos objetivos, como eliminar las fallas de los mercados para que sean eficientes en la asignación de recursos y en la fijación de precios,

\footnotetext{
${ }_{9}$ Para North, entre dos tecnologías en competencia se prefiere una de ellas así no sea la más eficiente, y esa preferencia es reforzada por una organización que reduzca los costos unitarios cuando aumenta la producción, por los efectos del aprendizaje que mejoran los productos o disminuyen los costos, por las ventajas de la cooperación con otros agentes y por las expectativas adaptativas. North usa el ejemplo del teclado QUERTY que no es el que produce los resultados más eficientes pero no se podido sustituir.
} 
lograr la estabilidad sistémica, hacer más equitativa la distribución del ingreso y la riqueza, erradicar la pobreza e incluir a la población en los beneficios del desarrollo. No obstante, en este caso también se puede perseguir el interés individual, considerando que el funcionario público que propicia el cambio satisface su propio interés teniendo éxito en su gestión, por ejemplo, diseñando normas o políticas que contribuyan a transformar y mejorar la sociedad ${ }^{10}$.

No es descabellado suponer que los cambios propuestos se facilitan en épocas de bonanza o expansión del ciclo económico, cuando el ambiente es propicio para adoptar las innovaciones y el mercado es más dinámico, es decir, cuando los empresarios están más dispuestos a innovar y adoptar nuevas tecnologías y nuevos mecanismos para evitar el riesgo o nuevos instrumentos de cobertura.

En tiempos de crisis, la preocupación es salvar a las entidades en peligro o, al menos, reducir el riesgo de las que se encuentren en problemas, aplazando el desarrollo de nuevos productos y procesos. En ese caso se activarían los mecanismos de seguridad que ponen en marcha las autoridades para controlar la crisis y evitar que vuelva a ocurrir. Aunque no se descarta la aparición de nuevos productos, pues las crisis son propicias para llevar a cabo iniciativas que conduzcan a la recuperación.

\section{OFERTA PÚBLICA DE TÍTULOS EN PROCESOS DE TITULARIZACIÓN}

Para examinar la incidencia de la regulación en el desarrollo de la titularización, el periodo de estudio se divide en dos: de 1993 a 2002 y de 2003 a 2013, dada la importancia del inicio de actividades de la sociedad titularizadora en 2002. La información proviene de diversas bases de datos de ofertas públicas aprobadas, que se homologaron para conseguir una base uniforme: el Registro Nacional de Valores e Intermediarios (RNVeI) de la Superintendencia de Valores (SV) para 1993-2005, y el RNVE de la SFC para 2006-2013 ${ }^{11}$; en materia de regulación, de los archivos de normas del Boletín de Hacienda, capítulo Superintendencia de Valores (hasta 2005), y del Ministerio de Hacienda y Crédito Público (MHCP) para los decretos expedidos

\footnotetext{
${ }^{10} \mathrm{La}$ teoría indica que los funcionarios buscan mantenerse en su cargo reforzando su poder o controlando el presupuesto, o hacer méritos para pasar al sector privado u organismos multilaterales con mejores salarios, un paso que se conoce como "puerta giratoria". Ver el documental Inside Job de Charles Ferguson (2008).

${ }^{11}$ Cifras de ofertas públicas autorizadas. El RNVE fue separado del RNVeI por la Ley 964 de 2005, y hace parte del Sistema Integral de Información del Mercado de Valores (SIMEV) (Ley 964 de 2005, art. 7. ${ }^{\circ}$ y ss.).
} 
desde 2006; y en materia de leyes, de los archivos digitales de la Secretaría del Congreso.

\section{OFERTA PÚBLICA DE TITULARIZACIONES, 1993-2013}

La titularización de activos es uno de los casos en que hay una respuesta del mercado a la expedición de normas. A partir de la regulación expedida en 1993, que luego formó parte de la Resolución 400 de 1995 Única de la extinta Sala General de la SV (Blanco, 2004) ${ }^{12}$, se inició en el país la titularización de activos de diversa índole-cartera hipotecaria, documentos de crédito y flujos de caja futuros, entre otros-; y la titularización agropecuaria comenzó a partir de la $\mathrm{Re}-$ solución 822-1 de 1999, que fue modificada por el Decreto 1340 de 2008. Como quedó contemplado en la regulación, el vehículo para realizar esos procesos fue el agente de manejo o sociedad fiduciaria, que constituía un contrato de fiducia mercantil o encargo fiduciario con el originador y un patrimonio autónomo con el bien fideicomitido (el subyacente de la titularización); el originador emitía títulos de contenido crediticio, de participación o mixtos (ibíd., 2003).

Otro hito importante fue la crisis de la banca hipotecaria de 1998 a 1999, que se enfrentó expidiendo la Ley 546 de 1999, atendiendo a la decisión de la Corte Constitucional (Cuéllar, 2006) ${ }^{13}$. Esta ley estableció, entre otras medidas, la constitución de sociedades titularizadoras de objeto social exclusivo (único vehículo para realizar la titularización hipotecaria), que seguirían el modelo de las entidades existentes en Estados Unidos desde los años treinta (Blanco, 2004). Dicha sociedad, así como los bancos comerciales hipotecarios, podría emitir títulos hipotecarios para recaudar en el mercado de capitales (supuestamente de inversionistas institucionales) recursos para financiar la compra de vivienda mediante crédito, y así superar la grave brecha de plazos de tales entidades financieras ${ }^{14}$.

\footnotetext{
${ }^{12}$ En la práctica, esa Resolución fue el estatuto del mercado público de valores hasta la expedición del Decreto 2555 de 2010, Decreto Único Financiero, que la absorbió. La SV se fusionó en 2005 con la Superintendencia Bancaria (SB) en la SFC. La Sala General fue eliminada por la Ley 964 de 2005, que estableció como regulador único del mercado de valores al Gobierno nacional, en cabeza del MHCP.

${ }_{13}$ Ver el cuadro 1 y, además, las sentencias C-700 y C-747 de 1999 de la Corte Constitucional.

${ }^{14}$ La Ley 546 de 1999 obligó a las antiguas corporaciones de ahorro y vivienda (CAV), que pertenecían al sistema UPAC, a convertirse en bancos hipotecarios o desaparecer. Un problema estructural de las CAV era que otorgaban créditos a 15 años y debían financiarse con recursos del público a la vista o a noventa días; ver Blanco (2010).
} 
Las superintendencias Bancaria y de Valores emitieron diversas normas en materia contable y de control de riesgo en los años noventa, y además se expidió la regulación tributaria para los originadores e inversionistas de algunos de los procesos, y para la oferta pública en general, en lo que concierne a información relevante y otros aspectos. Todo lo cual hizo posible el desarrollo de la titularización.

Cuadro 1

Regulación de la titularización hipotecaria, 1999-2002 ${ }^{15}$

\begin{tabular}{|c|c|c|}
\hline Emisor & Norma & Descripción \\
\hline Congreso & $\begin{array}{l}\text { Ley } 546 \text { de } \\
1999\end{array}$ & $\begin{array}{l}\text { Regula la concesión de créditos para la construcción y adquisición } \\
\text { de viviendas; establece las normas para la titularización de cartera } \\
\text { hipotecaria (crea las universalidades como subyacente de los procesos } \\
\text { de titularización, da paso a la constitución de sociedad titularizadora, } \\
\text { crea los títulos hipotecarios, entre otros); determina las condiciones } \\
\text { para la emisión de bonos hipotecarios; establece normas para la } \\
\text { financiación de vivienda de interés social VIS (el 25\% de la cartera } \\
\text { hipotecaria de los bancos comerciales hipotecarios deberá ser de } \\
\text { VIS); establece una exención tributaria a los tenedores de papeles } \\
\text { hipotecarios; establece el Fondo de Reserva para la Estabilización de } \\
\text { la Cartera Hipotecaria (FRECH). }\end{array}$ \\
\hline MHCP & $\begin{array}{l}\text { Decreto } 21 \text { de } \\
2001\end{array}$ & $\begin{array}{l}\text { Autoriza a los establecimientos de crédito y sociedades de servicios } \\
\text { financieros a efectuar inversiones en títulos hipotecarios que se } \\
\text { emitan. }\end{array}$ \\
\hline MHCP & $\begin{array}{l}\text { Decreto } 1719 \\
\text { de } 2001\end{array}$ & $\begin{array}{l}\text { Autoriza la constitución de una sociedad titularizadora y le fija obli- } \\
\text { gaciones de revelación de información. }\end{array}$ \\
\hline MHCP & $\begin{array}{l}\text { Decreto } 1782 \\
\text { de } 2001\end{array}$ & $\begin{array}{l}\text { Establece la garantía del Fondo de Garantías del Sistema Financiero } \\
\text { (Fogafín) a los títulos hipotecarios con subyacente constituido por } \\
\text { cartera VIS. }\end{array}$ \\
\hline SV & $\begin{array}{l}\text { Resolución } \\
117 \text { de } 2001\end{array}$ & $\begin{array}{l}\text { Establece la exigencia de capital mínimo para la sociedad titulariza- } \\
\text { dora. }\end{array}$ \\
\hline SV & $\begin{array}{l}\text { Resolución } \\
300 \text { de } 2001\end{array}$ & $\begin{array}{l}\text { Exige habilitación para desarrollar actividades comprendidas dentro } \\
\text { del objeto social, llevando a escritura pública el proyecto de estatutos } \\
\text { de la sociedad titularizadora. }\end{array}$ \\
\hline SV & $\begin{array}{l}\text { Resolución } \\
775 \text { de } 2001\end{array}$ & $\begin{array}{l}\text { Regula la titularización hipotecaria y la emisión en oferta pública de } \\
\text { títulos hipotecarios, teniendo como subyacentes: créditos hipoteca- } \\
\text { rios desembolsados o créditos hipotecarios futuros; establece que la } \\
\text { sociedad titularizadora es entidad vigilada; define contratos con el } \\
\text { administrador del subyacente y el representante legal de los tenedo- } \\
\text { res de títulos hipotecarios. }\end{array}$ \\
\hline SV & $\begin{array}{l}\text { Resolución } \\
179 \text { de } 2002\end{array}$ & $\begin{array}{l}\text { Precisa aspectos de la Resolución } 775 \text {, regula retitularización y emi- } \\
\text { sión de títulos hipotecarios en oferta privada. }\end{array}$ \\
\hline SV & $\begin{array}{l}\text { Resolución } \\
223 \text { de } 2002\end{array}$ & $\begin{array}{l}\text { Define que la sociedad titularizadora es emisor de valores; determina } \\
\text { la suficiencia de capital de la misma. }\end{array}$ \\
\hline SV & Resolución & $\begin{array}{l}\text { Precisa aspectos de la Resolución } 775 \text {, regula la retitularización y la } \\
\text { emisión de títulos hipotecarios en oferta privada. }\end{array}$ \\
\hline SB & $\begin{array}{l}\text { Circulares } 42, \\
50,51,58- \\
2001 \text { y } 11 \text { de } \\
2002\end{array}$ & $\begin{array}{l}\text { Regulan la gestión de riesgo de crédito y de mercado y fijan criterios } \\
\text { para su medición. }\end{array}$ \\
\hline
\end{tabular}

Fuente: Boletín de Hacienda, capítulo Superintendencia de Valores (hoy Superintendencia Financiera de Colombia), y Titularizadora Colombiana.

15 Sobre la regulación del periodo 1993-2002, ver Blanco (2004). Además de las normas mencionadas en el cuadro 1 , la sociedad titularizadora que se creara debía cumplir normas de buen gobierno corporativo (Resolución 275 de 2001, SV) y de prevención de actividades delictivas (Circular 004 de 1998, SB). 
La gráfica 1 muestra los montos totales autorizados por la SV (hoy SFC) para ser emitidos en oferta pública en procesos de titularización, entre 1993 y 2013; dichos montos muestran una tendencia creciente entre 1993 y 2001, excepto al final de la década, pues con la crisis de fin de siglo se produjo una paralización de la titularización hipotecaria, que se venía realizando con las reglas de la Resolución 400 de 1996 Unica, de gran impacto en la titularización en general.

Gráfica 1

Monto autorizado de oferta pública de títulos en procesos de titularización total 1993-2013

(Miles de millones de pesos corrientes)

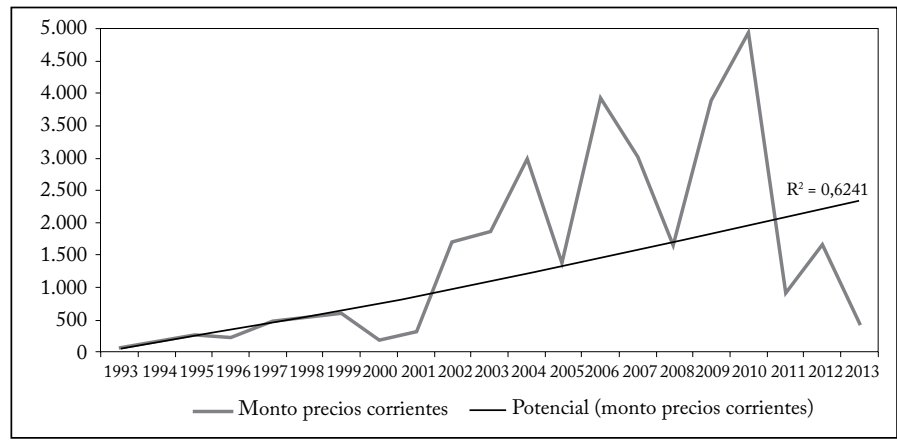

Fuente: RNVE, SFC, elaboración propia.

Con el inicio de actividades de la sociedad titularizadora en 2002, la tendencia negativa de la titularización de activos se tornó temporalmente positiva, con una fuerte recuperación de la titularización hipotecaria; en los años siguientes hubo visibles altibajos, y decayó en los últimos años. Desde 2003 y durante los diez años siguientes, el comportamiento de la titularización estuvo fuertemente influenciado por el número de procesos y los montos de la titularización hipotecaria autorizados por la SV, y desde 2006 por la SFC, sin solución de continuidad.

La gráfica 2 muestra el comportamiento de los montos autorizados para ser emitidos en oferta pública en procesos de titularización, esta vez en millones de pesos constantes de 1992. Aquí se observa una inflexión de la tendencia, ocasionada por el inicio de la titularización hipotecaria a través de sociedad titularizadora, cuyo volumen en 2013 fue en la práctica equivalente al autorizado en oferta pública en 1993. La diferencia es que en 1993 se trató de cuatro procesos de diversos subyacentes, cuando apenas arrancaba la titularización, mientras que en 2013 se contabilizó una sola autorización para una titularización de cartera hipotecaria. 
Gráfica 2

Monto autorizado de oferta pública de títulos en procesos de titularización total 1993-2013

(Miles de millones de pesos constantes de 1992)

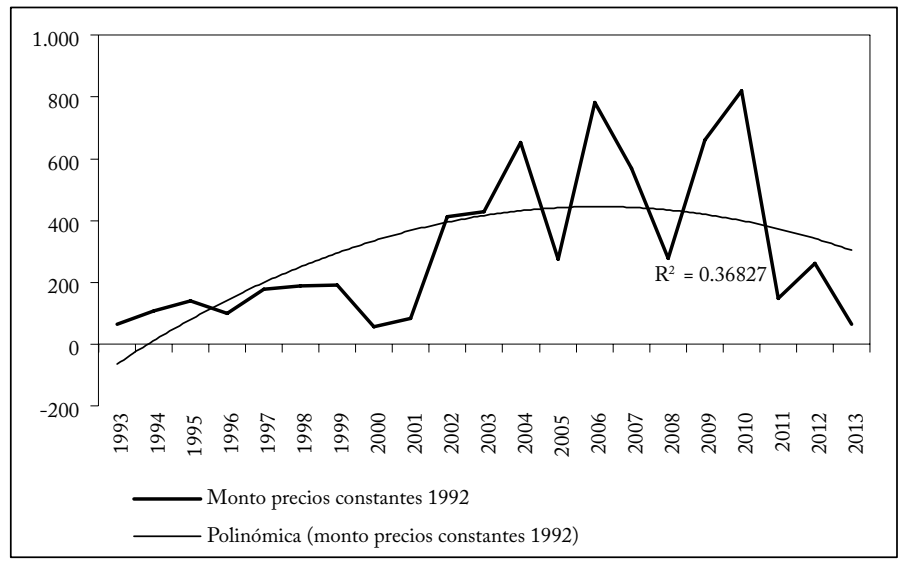

Fuente: RNVE, SFC; IPC: Dane; elaboración propia.

La titularización hizo una gran contribución a la oferta pública en todo el periodo: durante los veinte años que cubre el estudio, la participación de las titularizaciones en el total de ofertas fue muy significativa, llegando al 31,7\% en 2006. La titularización y las ofertas públicas mostraron altos crecimientos en algunos años: en 1996 las ofertas (211,6\%) y en 1997 las titularizaciones (108,7\%); en 2002 las ofertas $(170,2 \%)$ y las titularizaciones (437,6\%); en 2006 las titularizaciones (196,7\%), y en 2009 las ofertas y las titularizaciones (205,4\% y $141,4 \%$ respectivamente). Aunque ambas series muestran una tendencia creciente, la de la titularización es más débil.

La tendencia al menor crecimiento de la titularización con respecto a las ofertas públicas totales se ratifica cuando se observa el periodo 1993-2002. En ese periodo, los montos emitidos en titularizaciones correspondieron, en promedio, al 8,9\% de las ofertas totales, sin contar 2002, cuando la participación aumentó al 18,4\%.

En el periodo 2003-2013, lo más significativo fue que la titularización duplicó en promedio su participación en las ofertas totales por la presencia de la Sociedad Titularizadora Colombiana, pero esa participación tuvo una fuerte reducción relativa en los últimos años, especialmente en 2011 y 2013. Y aunque ambas series muestran una inflexión en la tendencia de crecimiento, que de ser positiva pasó a ser negativa, la desaceleración es mayor en la titularización que en las ofertas totales. 


\section{Gráfica 3}

Ofertas públicas vs. titularizaciones, 1993-2013

(Miles de millones de pesos)

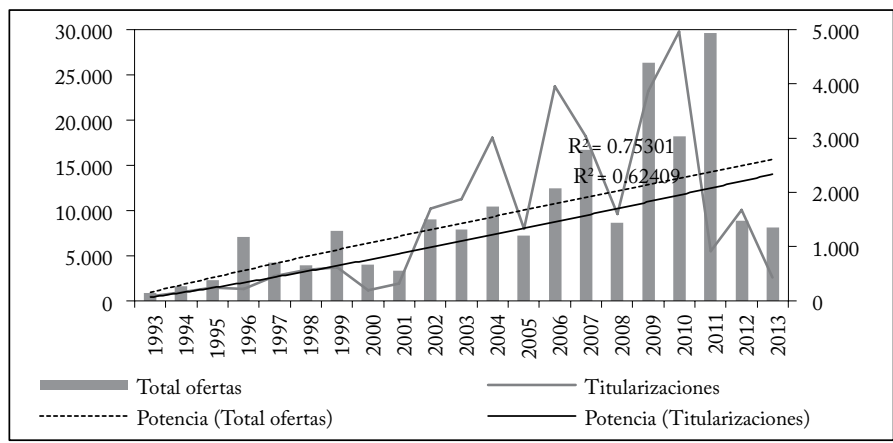

$\mathrm{R}^{2}$ ofertas: 0,7330; $\mathrm{R}^{2}$ titularizaciones: 0,6241.

Fuente: RNVE, SFC.

\section{Gráfica 4}

Montos de titularización y ofertas públicas totales (Miles de millones de pesos)

a) 1993-2002

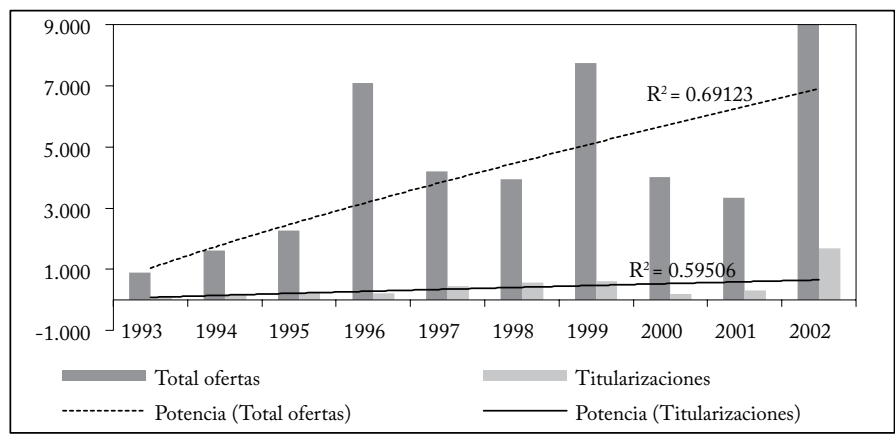

b) $2003-2013$

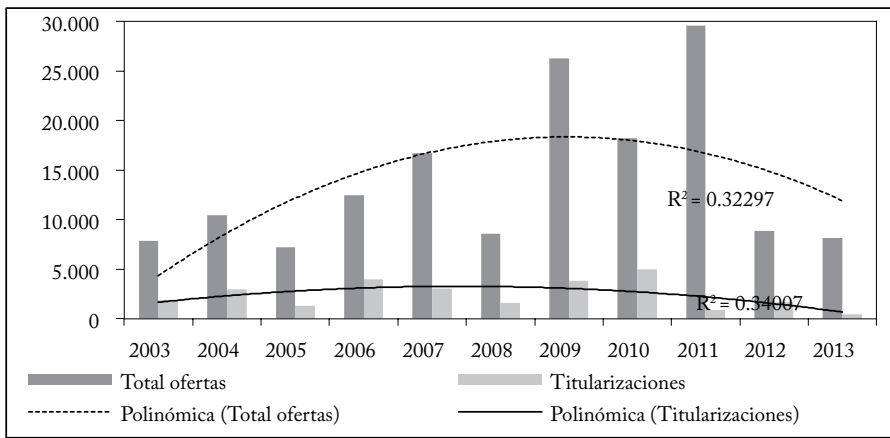

Fuente: RNVE, SFC, elaboración propia. 


\section{OFERTAS PÚBLICAS DE TITULARIZACIONES SEGÚN SUBYACENTE, 1993-2013}

Durante el periodo analizado se autorizaron 207 procesos de titularización con diversos subyacentes; se destacaron la titularización hipotecaria, con 62 procesos (29,9\% del total), la titularización de documentos y cartera de créditos, con 46 procesos $(22,2 \%)$, y la titularización inmobiliaria, con 35 procesos (16,9\%). Estos tres tipos de procesos cubrieron más de las dos terceras partes de los proyectos autorizados entre 1993 y 2013. También cabe destacar el comportamiento de los procesos cuyo subyacente fue el de flujos de caja futuros, y por su novedad conviene resaltar los procesos de titularización agropecuaria (ganadería de levante y proyectos agrícolas de tardío rendimiento). La titularización inmobiliaria y la agropecuaria perdieron fuerza en la segunda parte del periodo (2003-2013), lo que redujo el número de procesos por año, de un promedio de 11 entre 1993 y 2002 a un promedio de 9 entre 2003 y 2013.

Cuadro 2

Ofertas públicas de titularizaciones según subyacente (Millones de pesos corrientes)

\begin{tabular}{lrrrrrrrr}
\hline \multicolumn{1}{c}{ Tipo } & \multicolumn{4}{c}{$1993-2002$} & \multicolumn{4}{c}{$2003-2013$} \\
\hline & \multicolumn{1}{c}{ Monto } & \multicolumn{1}{c}{$\%$} & Número & \multicolumn{1}{c}{$\%$} & \multicolumn{1}{c}{ Monto } & \multicolumn{1}{c}{ Número } & $\%$ \\
\hline Hipotecaria & 2.020 .232 & 44,3 & 14 & 13,1 & 16.272 .730 & 61,0 & 48 & 48,0 \\
Documentos y cartera & 1.054 .366 & 23,1 & 21 & 19,6 & 3.974 .823 & 14,9 & 25 & 25,0 \\
Inmobiliaria & 611.609 & 13,4 & 33 & 30,8 & 1.085 .872 & 4,1 & 2 & 2,0 \\
Flujos futuros & 453.148 & 9,9 & 8 & 7,5 & 866.000 & 3,3 & 8 & 8,0 \\
Títulos. y acciones & 150.258 & 3,30 & 5 & 4,7 & 500.000 & 1,9 & 1 & 1,0 \\
Agropecuaria & 96.457 & 2,1 & 21 & 19,6 & 101.654 & 0,5 & 6 & 6,0 \\
Otros* & 173.400 & 3,80 & 5 & 5,6 & 3.862 .770 & 14,5 & 10 & 10,0 \\
Totales & 4.589 .470 & & 107 & & 26.663 .849 & & 100 & \\
\hline
\end{tabular}

* Otros incluye, en 1993-2002: proyectos de construcción (2 procesos), fondos inmobiliarios (4 procesos), fondos de valores ( 3 procesos), infraestructura ( 2 procesos); y en 2003-2013: títulos valores, bonos pensionales, infraestructura.

Fuente: RNVE,- SFC, última consulta 31-05-2013; elaboración propia.

Los promedios titularizados por proyecto (a pesos corrientes) aumentaron casi seis veces entre los dos subperiodos: de $\$ 42.495$ millones entre 1993 y 2002 a $\$ 266.638$ millones entre 2003 y 2013. En cuanto a la titularización hipotecaria, de un promedio de 1,4 procesos por año en 1993-2002 se llegó a más de 4 en promedio en 2003-2013, mientras que el valor medio por proyecto aumentó más de dos veces.

Lo más destacable entre 1993 y 2013 es el gran desempeño de la titularización hipotecaria: 62 procesos por $\$ 18,2$ billones hasta 1999 mediante agentes de manejo (patrimonio autónomo de sociedad fiduciaria), y desde 2002 mediante la Sociedad Titularizadora Co- 
lombiana ${ }^{16}$. Este monto corresponde al $58,6 \%$ de los montos totales autorizados en titularización durante todo el periodo.

\section{Gráfica 5}

Monto y número de titularizaciones por tipo de subyacente (Miles de millones de pesos corrientes)

a) 1993-2002

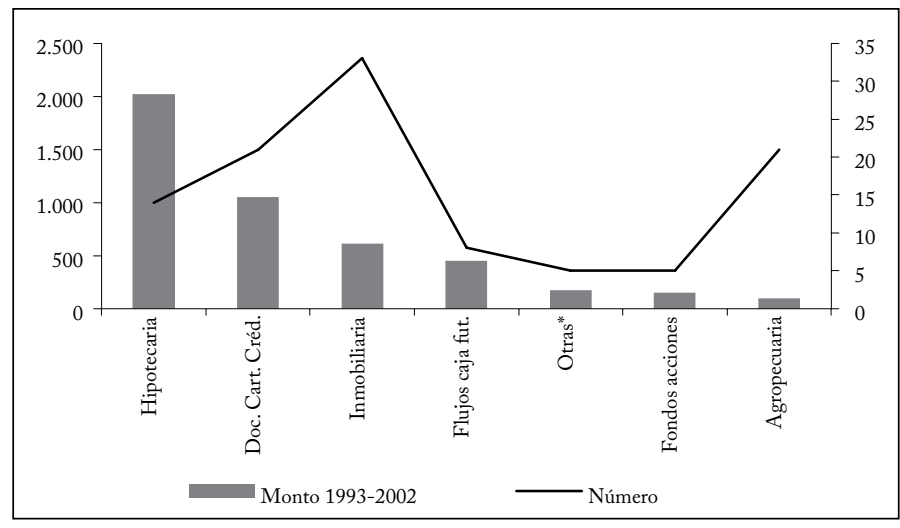

b) $2003-2013$

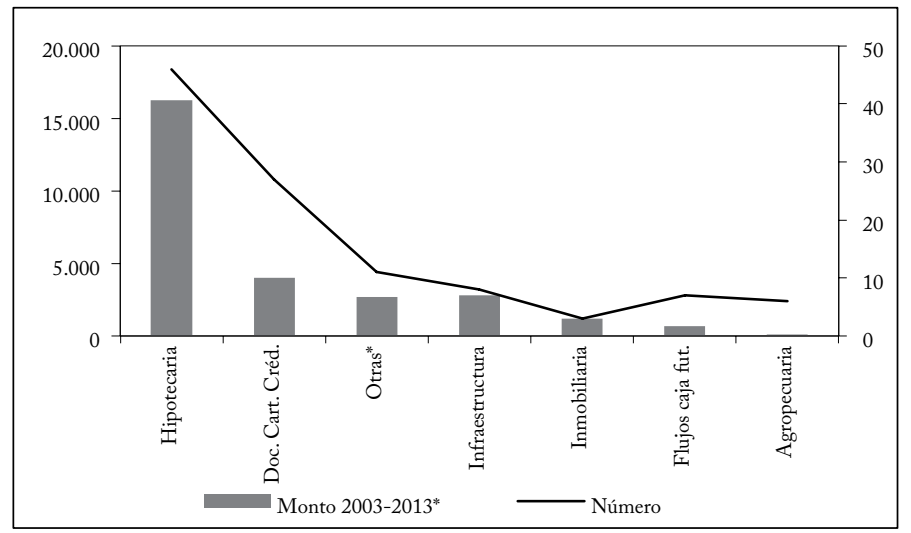

*Otros incluye: títulos valores, facturación, bonos pensionales, contratos de leasing, certificados, TES, proyectos de inversión.

Fuente: SIMEV/RNVE, SFC, elaboración propia.

Además, la observación detallada de la titularización hipotecaria indica que de los 46 procesos aprobados a la Titularizadora Colombiana en 2003-2013, la mayoría correspondió a TIPS, o títulos hipotecarios emitidos con base en universalidades constituidas por créditos en

${ }^{16}$ En 2000 y 2001 no se registraron autorizaciones de titularización hipotecaria. A partir de la Ley 546 de 1999, el único vehículo autorizado para realizar titularización hipotecaria es la Sociedad Titularizadora Colombiana, creada en 2001 y que opera desde 2002. 
UVR originados por bancos comerciales hipotecarios ${ }^{17}$. También se destacan los procesos de TIPS en pesos, cuyo subyacente son créditos hipotecarios en dicha denominación ${ }^{18}$. La Titularizadora Colombiana hizo ofertas en todo el periodo, pero sobresalen los años 2004, con 9 emisiones de TIPS, y 2010, con $6^{19}$. Además, la Titularizadora hizo tres emisiones de TECHS o retitularizaciones, dos en 2004 y una en 2005, que involucraron cartera perdida de los bancos comerciales hipotecarios y, por ende, emisiones de THBS de esos bancos, con títulos hipotecarios en oferta privada destinados a ser retitularizados.

En número y monto de procesos aprobados se destacó la titularización de documentos y cartera de crédito, con 46 titularizaciones por un valor de $\$ 5$ billones (el $16,1 \%$ del monto total), correspondiente a pagarés de emisores públicos -municipios y distritos- $\mathrm{y}$ a documentos para financiar el Transmilenio de Bogotá y a empresas privadas de diversos sectores, como minería, salud, alimentos y bebidas. Esta modalidad fue relativamente importante en la primera parte del periodo y en 2003, aunque después decayó y desde 2007 no se presentó ningún proyecto nuevo, hasta 2012 cuando se titularizó la cartera de una empresa textilera.

En materia de titularización inmobiliaria, la gran mayoría de los procesos se registró entre 1993 y 2002: de los 35 proyectos autorizados en el lapso de 20 años, por $\$ 1,7$ billones, a una diversa gama de originadores de los sectores real y financiero, 33 se aprobaron en los primeros 10 años, y hubo un alto número de titularizaciones y montos aprobados en 1997, 1999 y 2000. Estos proyectos desaparecieron a comienzos de la década anterior ${ }^{20}$.

Para finalizar esta breve reseña, cabe mencionar que la titularización agropecuaria también fue una respuesta a la expedición de una norma $^{21}$, con base en la cual se autorizaron 21 proyectos en un lapso

17 UVR o unidades de valor real sobre las que se pueden conceder créditos hipotecarios, según lo estableció la Ley 546 de 1999.

18 Según la Titularizadora Colombiana, de 32 procesos emitidos entre 2002 y 2010, el 50\% en número y monto correspondió a TIPS en pesos. La titularización hipotecaria incentivó la originación de créditos en tasa fija (Titularizadora, 2010).

19 La Titularizadora Colombiana emitió títulos hipotecarios por un promedio de $\$ 1,25$ billones anuales entre 2002 y 2009, y de $\$ 4$ billones hasta noviembre de 2010 (ibíd., 2010).

${ }^{20}$ La titularización dejó de ser una respuesta a la necesidad de financiar proyectos inmobiliarios. Hoy se emiten títulos de inversión para financiar este tipo de proyectos, como los FIDIS, que se presentan como productos fiduciarios, aunque se discute si constituyen o no valores $y$, por tanto, si su emisión debe ser autorizada como oferta pública. Para la industria, la titularización dejó de ser una opción por sus mayores costos de transacción.

${ }^{21}$ La Resolución 822-1 de 1999 de la Sala General, que modificó la Resolución 400 (art. 1.3.10.1, hoy art. 5.6.9.1.5 del Decreto 2555 de 2010), se expidió para atender necesidades del sector agropecuario. 
de tres años (entre 2000 y 2002), por un valor de $\$ 96.457$ millones, en su mayoría para ganadería de cría. Pero esta forma de titularización decayó y desapareció a mediados de la primera década del siglo, a pesar de la reforma de $2008^{22}$. En la segunda parte del periodo solo se aprobaron 6 proyectos por un valor mayor, $\$ 101.654$ millones: tres ganaderos, dos de banano y uno palmero (entre 2003 y 2005).

En síntesis, el desarrollo de la titularización fue una respuesta a la expedición del marco normativo que la impulsó; entre 1993 y 2002 la economía real respondió a la expedición de normas referentes a sus actividades y en los procesos de titularización se utilizó una gran diversidad de subyacentes que respondían a las necesidades de los agentes; durante el periodo 1993-2013 hubo un notable predominio de la titularización hipotecaria, especialmente en el segundo subperiodo, en número y en valor.

\section{EVALUACIÓN DEL MARCO ANALÍTICO NEOINSTITUCIONAL}

Antes de proceder a la evaluación, es necesario describir el contexto en el que la titularización provocó el cambio institucional. En los años noventa el mercado de valores colombiano se caracterizaba por "una falla de coordinación" entre la oferta y la demanda de títulos (MHCP, 1996): la baja oferta de títulos no incentivaba la aparición de demandantes, y los inversionistas no iban al mercado por la falta de títulos. Operaban tres Bolsas de Valores (Bogotá, Medellín y Occidente) donde se hacían las negociaciones del mercado secundario. Los títulos más cotizados eran valores de deuda pública y otros títulos de deuda que alcanzaban un 95\% de las negociaciones; el 5\% restante correspondía a un mercado accionario de poca profundidad.

En esos años hubo tres reformas que marcaron la pauta para el desarrollo del mercado. En primer lugar, la expedición en 1995 de la Resolución 400 que compiló todas las resoluciones de la Sala General -que por ley tenía la competencia de intervenir en el mercado a nombre del Estado- ${ }^{23}$ e incorporó las normas sobre titularización expedidas desde 1993. A comienzos de la década surgió la iniciativa de introducir instrumentos que se negociaban en el mercado internacional, como los títulos colateralizados en hipotecas, que representaban derechos sobre obligaciones con los bancos comerciales (en principio créditos hipotecarios) y se negociaban independientemente

22 Decreto 1340 de 2008.

${ }^{23}$ Ver los diversos informes de la SV, algunos de los cuales se encuentran en la página web de la SFC, y otros en medio físico. Para la primera parte del periodo, ver el informe final de la Misión de Estudios del Mercado de Capitales de 1995 (MHCP, 1996). Ley 35 de 1993, en particular arts. 4. ${ }^{\circ}$ y 33. 
de los subyacentes. Pero las normas jurídicas no contemplaban esta figura y era necesario modificar la regulación para definir productos, establecer las condiciones de negociación, determinar cómo debían contabilizarlos los originadores y los inversionistas, y otros aspectos.

En segundo lugar, la descoordinación mencionada fue resuelta en parte en la segunda mitad de la década organizando el mercado de deuda pública a través del sistema electrónico SEN para la negociación y del DCV para el depósito, la compensación y la liquidación de las operaciones, ambos administrados por el Banco de la República. Se suponía que un emisor con riesgo soberano promovería la entrada de inversionistas institucionales (fondos de pensiones y cesantías, carteras colectivas de inversión), como en efecto sucedió, y que la llegada de estos inversionistas incentivaría la salida de emisores privados, lo que también ocurrió.

En tercer lugar, la modificación de las normas de intermediación de valores permitió la operación de agentes como las entidades financieras en el mercado regulado, a las que la reforma de comienzos de los noventa les permitió tener posición propia en títulos valores y negociarlos en sus tesorerías. Esto llevó al surgimiento de un mercado extrabursátil a través de sistemas electrónicos, que se regularizó en 1996 cuando se modificó la definición de intermediación de valores y se amplió el número y el tipo de agentes a los que se consideraba intermediarios de valores, incluidos los bancos y los administradores de activos de terceros ${ }^{24}$.

Como resultado, los emisores de valores ofrecieron al mercado primario títulos tradicionales -bonos y acciones ordinarias-; en menor medida títulos nuevos - papeles comerciales y acciones con dividendo preferencial y sin derecho a voto- $y$, en forma creciente, títulos en procesos de titularización; así los bancos empezaron a ser actores importantes en la oferta pública de bonos ordinarios. No obstante, la deuda pública siguió predominando en el mercado.

A comienzos de siglo, después de la crisis de la década anterior, cabe destacar las reformas de la titularización hipotecaria, que la convirtieron en líder del mercado de títulos privados durante los primeros años. En 2001 se unificaron las tres Bolsas de Valores en la Bolsa de Valores de Colombia (BVC) y se creó el Mercado Electrónico Colombiano (MEC); el mercado de valores quedó conformado por tres plataformas de negociación: la de acciones en la BVC: la de títulos de deuda (bonos y papeles comerciales) y titularizaciones en el

${ }^{24}$ Resolución 1201 de 1996, que modificó la Resolución 400. La normatividad después fue reformada por el Decreto 1121 de 2008, y hoy hace parte del Decreto 2555 de 2010. 
MEC, y la de títulos de deuda pública en el SEN. Además, se expidió la Ley 964 de 2005, ley marco del mercado de valores, que adoptó los estándares internacionales de la IOSCO, y se consolidaron los sistemas de compensación y liquidación privada en DECEVAL y pública en DCV, creados en la segunda mitad de la década anterior. En esos años la oferta pública en el mercado primario sufrió altibajos, se mantuvo el predominio de los bonos y las acciones ordinarias entre los títulos tradicionales, y surgió con gran fuerza la titularización hipotecaria.

Aunque en la década actual no ha habido reformas interesantes, cabe destacar la creación del Mercado Integrado Latinomericano (MILA) por las bolsas de Colombia, Santiago (Chile) y Lima (Perú), que permite cotizar valores de los tres países ${ }^{25}$, y la creación de la Cámara de Riesgo Central de Contraparte (CRCC) en Colombia.

En este contexto y después de comentar la evolución de la titularización en el periodo 1993-2013, se evalúa el proceso de cambio usando el marco analítico propuesto por North:

Agente de cambio: aquí se tienen en cuenta el empresario como tal y el empresario político (Díaz, 2005). El primero se refiere a agentes $\mathrm{u}$ originadores de los sectores real y financiero que vieron la posibilidad de obtener, con la titularización, flujos de fondos de menor costo que con los procedimientos tradicionales de emisión de bonos o de acciones, y convertir en efectivo activos poco líquidos -inmuebles, documentos o cartera de crédito de mediano o largo plazo, portafolios de mediano o largo plazo, ganadería de cría o cultivos de tardío rendimiento-o anticipar flujos de caja-como los provenientes del recaudo de impuestos o de peajes en las carreteras, matrículas universitarias, rentas de parqueaderos, de contratos de leasing o de arrendamiento de inmuebles-,y que requerían un marco normativo que diera seguridad jurídica a los procedimientos, especialmente en los años noventa.

Desde 2002 hasta comienzos de la década siguiente, la innovación y potencial reducción de los costos de transacción se manifestó en la titularización hipotecaria a través de una sociedad titularizadora, cuya operación daría lugar a varios avances: estandarización y adopción de mejores prácticas en los estudios, aceleración de la concesión y el desembolso de créditos hipotecarios, mejoramiento de la metodología para avaluar inmuebles, sistematización de la documentación

25 Hace poco se anunció la integración de la Bolsa Mexicana de Valores al MILA, con lo que su capitalización de mercado llegaría a un billón de dólares, y de BOVESPA (Brasil), la plaza más grande de Iberoamérica. Ver [http:// gestion.pe/mercados/bolsa-mexicana-valores-asegura-que-se-integrara-al-milafin-ano-2100744], [http://www.am.com.mx/leon/negocios/la-bolsa-mexicana-sesumara-a-mila-118365.html] y [http://www.dinero.com/inversionistas/articulo/ bolsas-valores-integran-mila/197671]. 
de pagarés e hipotecas, unificación de los sistemas de amortización, mejoramiento de los procesos de cobranza y capacitación a los deudores (Titularizadora, 2010).

Por su parte, los "empresarios" políticos decidieron modificar el marco normativo, más en concreto el regulador del mercado de valores (la Sala General de la SV hasta 2005 y el MHCP desde 2006), buscando dotar de nuevos productos al mercado, promover la desintermediación y canalizar recursos del mercado de capitales a la financiación de activos de largo plazo, entre otros objetivos teóricos.

Fuente de cambio: en los años noventa el proceso de titularización fue impulsado por la Bolsa de Bogotá y la SV, y se aprendió cómo operaba el mercado secundario de hipotecas en Estados Unidos, a partir de la experiencia de grandes titularizadoras como Fannie Mae y Freddie Mac. Cabe resaltar, además, el desarrollo del negocio fiduciario, especialmente de proyectos inmobiliarios financiados con certificados de participación en esos proyectos, cuya rentabilidad reflejaba inicialmente su valorización ${ }^{26}$; y la posibilidad de anticipar caja en proyectos de levante de ganado y otros proyectos agropecuarios que pusieron en circulación los títulos ganaderos en 1999. Aunque la expedición de la norma en 1999 dio lugar a un activo proceso de titularización ganadera en los años siguientes que llamó la atención de los reguladores y del mercado en el contexto internacional, después de 2005 no se registró ningún proceso nuevo, a pesar de la expedición de una nueva norma en 2008.

Otra fuente de cambio que afectó los precios relativos de la financiación fue la crisis hipotecaria de 1998-1999, que llevó al derrumbe del sistema UPAC, obligó a proponer medidas para impedir el colapso de la financiación de vivienda y a establecer soluciones de fondo al grave descalce de plazos de los bancos hipotecarios; esto último canalizando recursos de los inversionistas en el mercado de capitales a través de una sociedad titularizadora, que titularizara créditos hipotecarios y retitularizara documentos emitidos sobre esos créditos.

${ }^{26}$ Los títulos Oikos se empezaron a emitir a comienzos de los noventa, y el regulador consideró que no eran títulos públicos sino de emisión privada. No obstante, se llegaron a negociar en la Bolsa de Occidente; ver [http://www.eltiempo. com/archivo/documento/MAM-423477]. Al expedirse la regulación de 1993, se estableció un plan de ajuste a las nuevas condiciones de emisión en oferta pública mediante la Circular Externa 17 del 20 de octubre de 1994 de la SV. Hoy se ofrecen como fiducia inmobiliaria; ver [http://www.oikos.com.co/titulos/Fiducia-Inmobiliaria].

La reforma de 2008 se realizó mediante el Decreto 1340 de 2008, art. 6. ${ }^{\circ}$ y ss. Este decreto se referencia en Faolex, página web de la FAO. E1 hecho de que no haya nuevos procesos indicaría que la titularización se agotó como opción de financiación. 
Proceso de cambio: ocurrió inicialmente con la construcción de un marco regulatorio que reconoció nuevos contratos y la emisión de títulos en procesos de titularización que tendrían "las características y prerrogativas de los títulos valores" 27 ; y, luego, con el desarrollo del marco normativo de la titularización y retitularización hipotecaria realizada por una sociedad titularizadora. Todo ello fue acompañado de ajustes a la regulación de los subyacentes y las normas contables, de las garantías y de la administración de riesgo. El instrumento para este proceso de cambio fue la regulación de la titularización de activos con diversos subyacentes en 1993, de la Sala General de la SV; regulación complementada en 2000 por la misma Sala con la posibilidad de titularización agropecuaria, y con la expedición de las normas de titularización hipotecaria en 1999 por el Congreso, las cuales fueron reglamentadas por la SV en primera instancia, y por el MHCP y la SB en lo de su competencia.

Parte importante de este marco institucional fue la regulación tributaria, que tuvo gran impacto en el comportamiento de la titularización hipotecaria como se verá más adelante.

Vía del cambio: el marco institucional de la titularización, que hizo posible emitir productos financieros novedosos, cambió la "trayectoria" en varios aspectos: la definición de productos más complejos que los que se negociaban antes y que se considerarían valores; la posibilidad de financiarse sin ser emisor de papeles, con opciones distintas a la emisión de derechos de crédito (bonos o papeles comerciales) o participación (acciones); la conversión de activos no líquidos en efectivo sin afectar sustancialmente el tamaño del balance de los originadores, y el traslado del riesgo de los subyacentes al mercado de capitales, entre otros aspectos.

Entre las ventajas de la titularización hipotecaria para las entidades originadoras cabe mencionar la posibilidad de obtener mayores recursos, la estandarización del sector y la reducción de las tasas de crédito hipotecario con un efecto positivo potencial en la demanda. Además, contribuyó a profundizar el mercado de capitales, pues cerca del $10 \%$ de las transacciones en el mercado secundario entre 2002 y 2010 fue en títulos hipotecarios (Titularizadora, 2010).

El análisis de esta sección lleva a concluir que la regulación provocó un cambio favorable para el desarrollo de productos de financiación innovadores, que perduró y modificó los contratos, procedimientos y acuerdos, así como la mentalidad de los agentes. Pero aunque de

${ }^{27}$ Resolución 400 de la Sala General de la SV, art. 1.3.1.6. (hoy art. 5.6.1.1.6 del Decreto 2555 de 2010). 
acuerdo con North estos cambios deberían tener grandes repercusiones en el desarrollo, los resultados recientes parecen indicar que la fuerza de los nuevos productos desapareció, quizá por el hecho de haberse vuelto más costosos que los tradicionales. La titularización no solo dejó de jalar el mercado, como antes, sino que no ha sido sustituida por otra innovación.

\section{FACTORES QUE INCIDEN EN LATITULARIZACIÓN EN COLOMBIA}

Para complementar la revisión anterior es necesario examinar algunos factores que explican el desarrollo de la titularización desde el punto de vista de la oferta y la demanda de títulos.

Cuadro 3

Titularizaciones por sector económico, 1993-2013

(Millones de pesos)

\begin{tabular}{ccrrrrr}
\hline \multirow{2}{*}{ Año } & \multicolumn{2}{c}{ Primario } & \multicolumn{2}{c}{ Secundario } & \multicolumn{2}{c}{ Terciario } \\
\cline { 2 - 7 } & Número & \multicolumn{1}{c}{ Monto } & Número & \multicolumn{1}{c}{ Monto } & Número & \multicolumn{1}{c}{ Monto } \\
\hline 1993 & 0 & 0 & 2 & 20.091 & 2 & 59.258 \\
1994 & 0 & 0 & 5 & 66.616 & 3 & 93.000 \\
1995 & 0 & 0 & 1 & 10.000 & 7 & 240.024 \\
1996 & 0 & 0 & 1 & 5.962 & 11 & 212.439 \\
1997 & 0 & 0 & 3 & 24.651 & 14 & 431.145 \\
1998 & 0 & 0 & 2 & 30.116 & 4 & 536.471 \\
1999 & 0 & 0 & 5 & 241.703 & 10 & 379.954 \\
2000 & 4 & 12.941 & 3 & 125.454 & 2 & 57.627 \\
2001 & 8 & 32.822 & 2 & 79.046 & 2 & 203.689 \\
2002 & 9 & 50.693 & 1 & 40.000 & 6 & 1.605 .757 \\
2003 & 2 & 8.240 & 7 & 586.105 & 7 & 1.277 .733 \\
2004 & 2 & 23.414 & 4 & 961.953 & 12 & 2.027 .117 \\
2005 & 2 & 70.000 & 3 & 258.000 & 8 & 1.002 .867 \\
2006 & 0 & 0 & 6 & 1.450 .075 & 8 & 2.498 .887 \\
2007 & 0 & 0 & 1 & 500.000 & 7 & 2.535 .890 \\
2008 & 0 & 0 & 0 & 0 & 5 & 1.601 .223 \\
2009 & 0 & 0 & 3 & 2.284 .995 & 4 & 1.580 .400 \\
2010 & 0 & 0 & 1 & 100.000 & 8 & 4.866 .596 \\
2011 & 0 & 0 & 0 & 0 & 3 & 921.283 \\
2012 & 0 & 0 & 1 & 35.000 & 5 & 1.646 .046 \\
2013 & 0 & 0 & 0 & 0 & 1 & 428.025 \\
\hline
\end{tabular}

Clasificación propia según el sector económico al que pertenece el originador.

Fuente: RNVE, SV y SFC; última consulta, 31 de mayo de 2104.

En un trabajo sobre la oferta pública (Blanco, 2008) se mostró que la emisión de valores en el mercado primario, tanto de emisores públicos como privados, no parecía estar determinada por el comportamiento de la economía en el largo plazo, aunque este tenía alguna importancia en las decisiones de financiación, especialmente en la parte baja del ciclo, y que esa importancia podía aumentar en el corto plazo. También se indicó que en dichas decisiones incidían el costo y el acceso 
a otras fuentes de financiación, como el crédito bancario, los altos costos de transacción de la emisión de papeles, el desconocimiento del funcionamiento del mercado y la baja demanda de papeles.

No hay un número suficiente de observaciones para hacer un ejercicio similar en el caso de la titularización, y no se puede determinar la correlación entre el comportamiento de esta forma de emisión y el de la economía, y aún menos con el comportamiento de cada sector (agropecuario, manufacturero, servicios). No obstante, la información disponible indica que la mayor parte de los procesos de titularización fue emprendida por originadores del sector terciario, lo que se explica por la gran fuerza de la titularización entre originadores del sector financiero. De hecho, en 1993-2013, los originadores del sector servicios realizaron un $62,3 \%$ de las titularizaciones, con un $77,5 \%$ del monto total; los del sector secundario, un $24,6 \%$, con un $21,8 \%$ del monto; y los del sector primario, un 13\%, con apenas el 0,6\% del monto titularizado.

En cuanto al promedio del monto titularizado, el más pequeño fue el del sector primario, $\$ 7.337,4$ millones por proceso; en el sector secundario fue de $\$ 133.720$, 4 millones, y en el sector terciario de $\$ 187.639,0$ millones. Estas cifras son importantes porque algunos costos de estructuración, calificación y colocación de las emisiones en oferta pública no se cobran por el tamaño de la titularización sino por cada emisión, lo que hace más costosos los procesos de menor valor. Y se suman a los que dependen del tamaño de la emisión, como los de inscripción y mantenimiento en el Registro y en el sistema de negociación, depósito, administración de la emisión y garantías otorgadas.

\section{LA OFERTA DE TITULARIZACIÓN NO HIPOTECARIA, 1993-2013}

La decisión de titularizar un activo para lograr caja depende en mayor medida de factores microeconómicos, como el costo del capital y el peso de la tasa de interés en la estructura de costos de los proyectos. Un originador puede preferir esta forma de financiación porque su tasa es menor que la del crédito bancario. Entre 1993 y 2013 los originadores de titularizaciones consiguieron las tasas de crédito que se muestran en la gráfica 6.

Aunque hay una relación directa entre la titularización no hipotecaria y las tasas de interés, la correlación no es significativa. Mientras que las tasas de interés disminuyeron entre 2003 y 2013, el monto de los procesos de titularización no hipotecaria tuvo un comportamiento irregular, y en tres años no hubo titularizaciones: en 2008, cuando estalló la crisis mundial y el riesgo de la economía aumentó, y por 
tanto también las tasas de interés; en 2011, cuando se elevaron las tasas, y en 2013, cuando se redujeron. En 2010 y 2012 se registraron montos de titularización relativamente bajos.

Gráfica 6

Tasa de interés de colocación del sistema financiero, 2003-2013 (semanal) a) Tasas de crédito ordinario

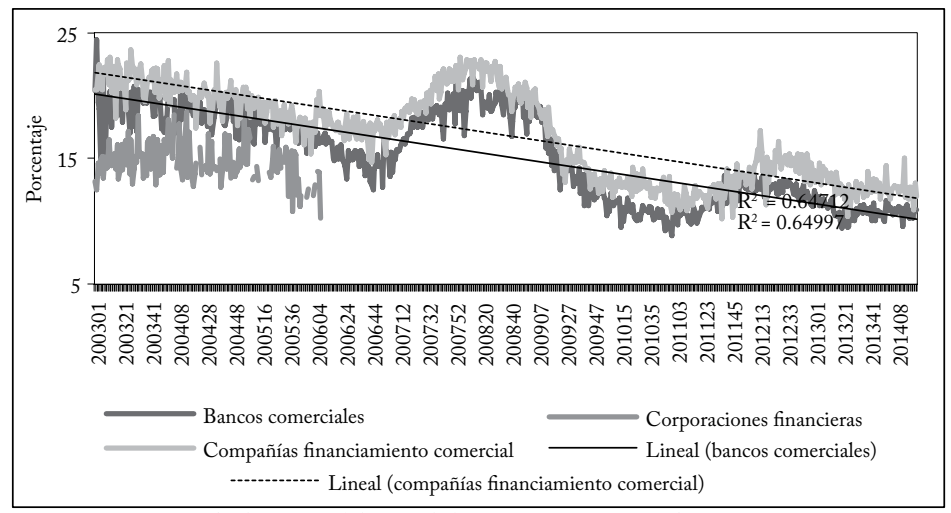

Fuente: Banco de la República, elaboración propia. de Financiamiento

b) Tasa de crédito ordinario de los bancos y monto de titularización no hipotecaria

(Millones de pesos)

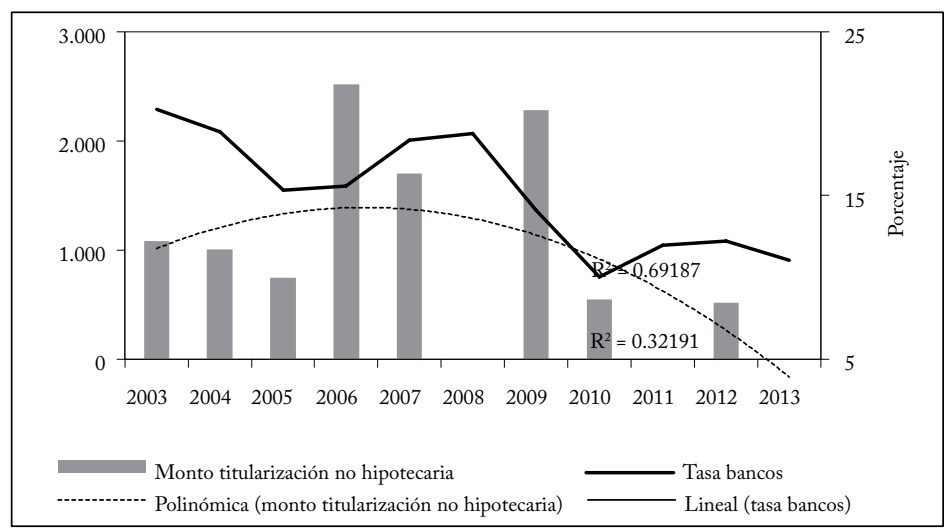

$\mathrm{R}^{2}=0,294786$.

Fuente: tasas: Banco de la República; monto de titularización: RNVE, SFC. Elaboración propia.

La disminución del número y del monto de titularizaciones no hipotecarias en los últimos años sugiere que no hay incentivos para este tipo de procesos, aunque las tasas de interés sean bajas. Esto quizá obedezca a que los menores costos teóricos de la titularización no 
son un incentivo para que esta forma de financiación sea preferible al crédito ordinario ${ }^{28}$.

\section{LA OFERTA DE TITULARIZACIÓN HIPOTECARIA, 2003-2013}

A diferencia de la titularización en general, el comportamiento de la titularización hipotecaria, que representa el 58,6\% del monto autorizado en el periodo, se puede correlacionar con el comportamiento del PIB de la construcción dado el mayor número de observaciones, y porque la principal fuente de financiación para construir vivienda es el sector financiero y un alto volumen de créditos para compra de vivienda es titularizado: según la Titularizadora Colombiana, en 2010 estaba titularizado el 38\% de los créditos, y las titularizaciones representaban entre el 30\% y el 50\% de los desembolsos (Titularizadora, 2010).

El primer supuesto del análisis es que se recurre a la titularización por sus menores costos frente a la emisión de bonos. Los bancos hipotecarios no utilizaron los bonos hipotecarios establecidos por la regulación para financiar sus créditos hipotecarios ${ }^{29}$. El segundo supuesto es que las decisiones de los estructuradores de los procesos están relacionadas con el ciclo del sector de la construcción. Cabe señalar que la participación en el PIB del sector de la construcción, incluidas edificaciones y obras civiles ${ }^{30}$, aumentó en 1991-1996 y 2000-2013 (no hay información para 1997-1999), y que pasó del 3,4\% en 1993 al 7,9\% en $2013^{31}$. Las edificaciones representaron un 50\% del PIB de la construcción entre 2003 y 2013 (aunque en los últimos tres años se redujeron a menos del $46 \%)^{32}$.

La correlación entre el comportamiento de la titularización hipotecaria y el crecimiento del PIB de edificaciones entre 2003 y 2013 se determinó teniendo en cuenta que esa titularización corresponde en su totalidad a subyacentes constituidos por créditos hipotecarios para compra de vivienda, y la presumible alta participación de la

${ }^{28}$ Esta consideración se podría generalizar a las demás ofertas públicas de los últimos años, dada su tendencia decreciente en la última parte del periodo.

${ }^{29}$ La Ley 546 de 1999, art. 9. ${ }^{\circ}$, estableció la emisión de bonos hipotecarios en UVR, sin que el crédito implicara desembolso de efectivo del emisor, pero no fue utilizada por los bancos. La Resolución 542 de 2002 de la SV permitió emitir bonos hipotecarios estructurados sobre créditos hipotecarios creados previamente en el balance del originador. Esta modalidad fue utilizada en cinco ocasiones (Blanco, 2010). En 2013, la SFC autorizó la emisión de $\$ 103,9$ millones en bonos hipotecarios a 15 años a una compañía de financiamiento comercial.

${ }^{30}$ En cuentas nacionales corresponde a edificaciones completas, partes de edificaciones y acondicionamiento de edificaciones.

${ }^{31}$ Metodología del Dane de 1994.

ju909y Metodo*logía del Dane de 2005. 
construcción de vivienda en el total de edificaciones. Se encontró una correlación directa, aunque no muy alta, entre la titularización hipotecaria a precios constantes y el PIB de edificaciones, lo que sugiere una influencia positiva del comportamiento reciente de la construcción de edificaciones en las decisiones de titularización hipotecaria. La relación cambia cuando el PIB de edificaciones se rezaga un año, pero con una mayor correlación.

\section{Gráfica 7}

Participación de la construcción en el PIB, 1991-2013

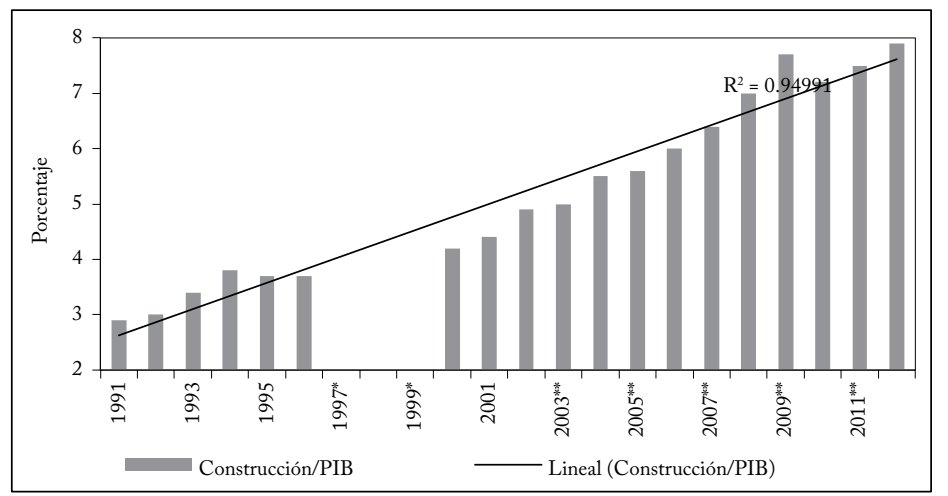

E1 PIB de la construcción está compuesto por obras civiles y edificaciones.

* Años sin información; ** Datos provisionales.

Fuente: Dane, metodología de 1994, elaboración propia.

\section{Gráfica 8}

Participación de las edificaciones en el PIB de la construcción, 2000-2013

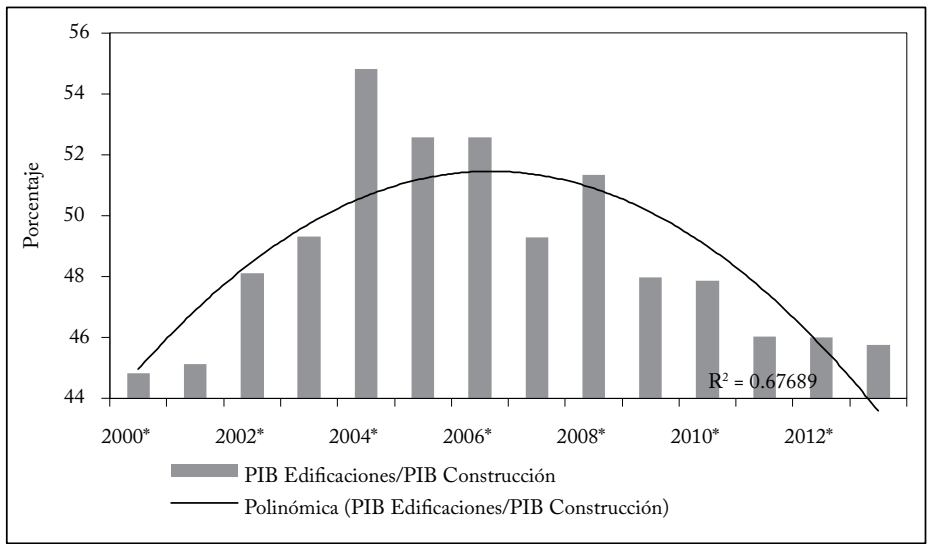

* Todos los datos son provisionales.

Fuente: Dane, metodología de 2005, elaboración propia. 


\section{Gráfica 9}

Variación de la titularización hipotecaria y del PIB de edificaciones, 2003 y 2013

(Precios constantes)

a) PIB de edificaciones del periodo

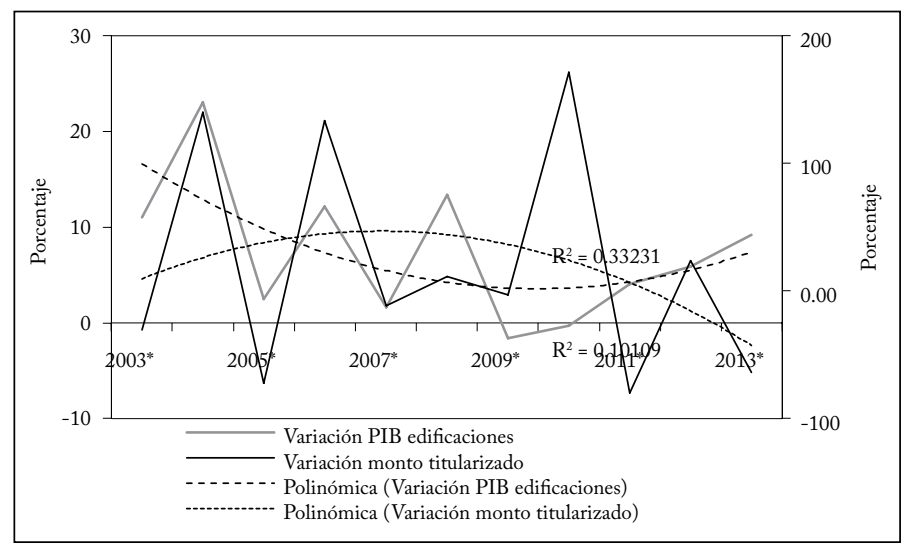

b) PIB de edificaciones rezagado un periodo

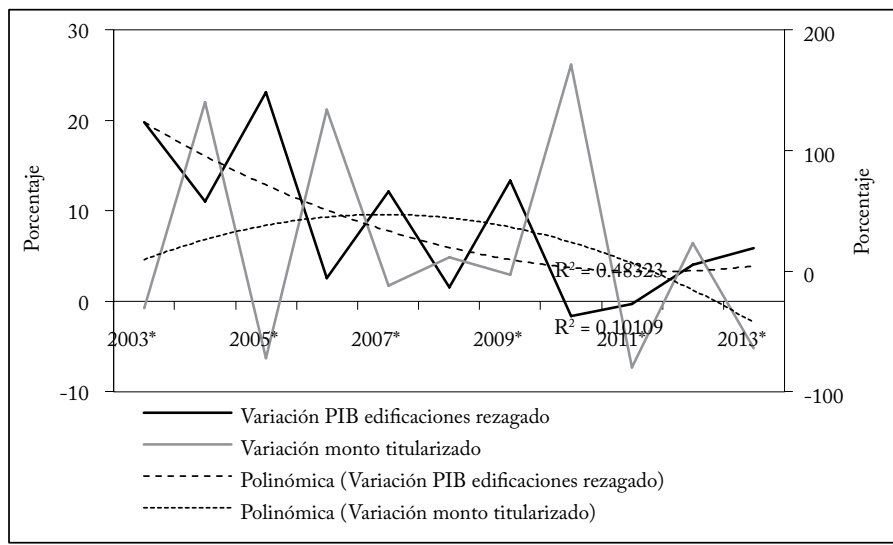

$\mathrm{R}^{2}$ Tit. Hip. Pr. Ctes. a PIB edificaciones periodo presente: 0,3131; $\mathrm{R}^{2}$ Tit. Hip. Pr. Ctes. a PIB edificaciones rezagada: $-0,3953$.

Fuente: Titularización: SFC; IPC y PIB: Dane; elaboración propia.

Debido a la baja correlación entre las variables es necesario buscar otros determinantes de la decisión de titularizar cartera hipotecaria. Entre ellos la división de la cartera hipotecaria entre créditos para vivienda de interés social (VIS) y créditos para otras categorías (no VIS), que son la mayor parte. Los saldos de cartera titularizada en 2003-2013 muestran un predominio en todos los años de la cartera no VIS, que llegó a un máximo del 93,5\% en 2009, y se redujo a un 
$87 \%$ a finales de 2013. En 2003, la cartera VIS era casi la tercera parte $(31,8 \%)$ de los saldos de créditos titularizados, pero este porcentaje cayó sistemáticamente y llegó a un mínimo del 6,5\% en 2009. En la alta participación de la vivienda VIS en la cartera titularizada total quizá incidieron dos aspectos: que, para cumplir el mínimo del 25\% de cartera VIS que debían conceder los bancos hipotecarios, se contabilizaban los montos titularizados en este tipo de cartera ${ }^{33}$, y la autorización al Fogafín para garantizar la titularización de cartera VIS ${ }^{34}$.

Gráfica 10

Cartera titularizada a fin de año, 2003-2013

(Miles de millones de pesos corrientes))

a) Saldos de cartera titularizada a fin de año, 2003-2013

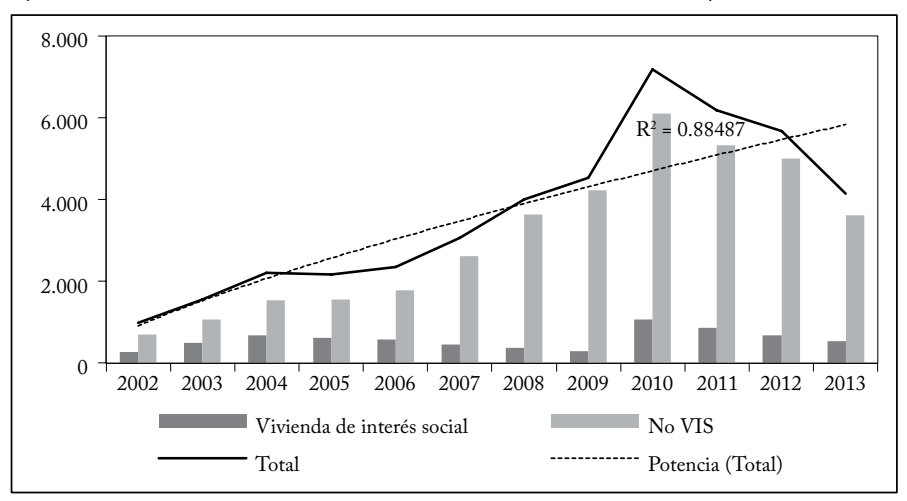

b) Composición cartera titularizada VIS-no VIS a fin de año, 2003-2013

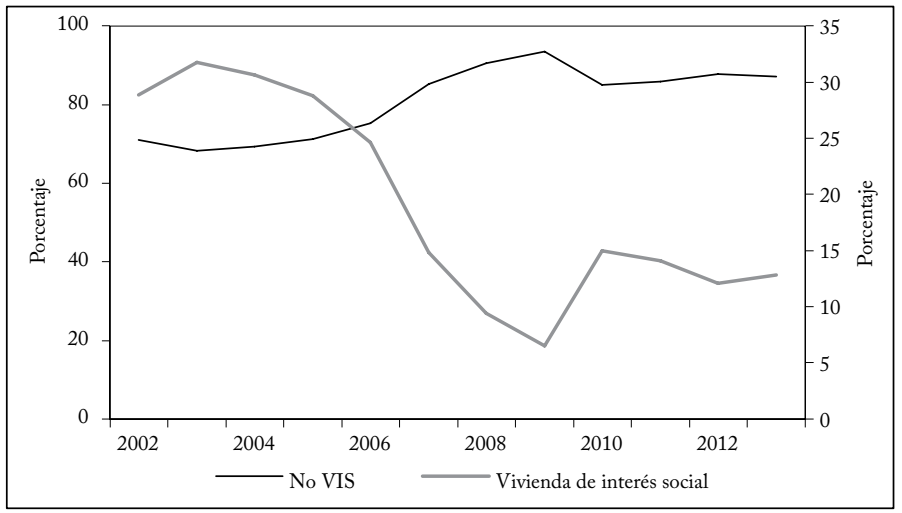

No incluye titularizaciones TECH.

Fuente: Titularizadora Colombiana, elaboración propia.

33 Art. 28, Ley 546 de 1999.

34 Decreto 1782 de 2001. 
Además, a pesar del estímulo tributario que buscaba que los bancos hipotecarios financiaran este tipo de vivienda, que regiría a partir de $2005^{35}$, el saldo de cartera VIS titularizada en el total decayó en 20062009. Sin embargo, a finales de 2010 (último año de ese beneficio tributario) llegó a un máximo de $\$ 1,1$ billones, con el mayor monto de cartera titularizada en todo el periodo ${ }^{36}$. En 2010 también se llegó al máximo valor de cartera titularizada en todo el periodo, $\$ 6,1$ billones. Desde ese año los saldos totales volvieron a caer sistemáticamente, hasta $\$ 4,1$ billones en 2013 , cerca del nivel registrado cinco años atrás. De dicho valor, \$531.202 millones, el 12,8\%, correspondía a cartera VIS.

Otro elemento que explica en parte las decisiones de titularización fue la necesidad de sacar la cartera hipotecaria de menor calidad como la cartera perdida- de los balances de las entidades financieras; lo que dio origen a tres procesos de retitularización de este tipo de cartera, por $\$ 405.466,6$ millones, en los que se emitieron títulos TECH.

\section{EL RÉGIMEN TRIBUTARIO Y LA ADQUISICIÓN DE TÍTULOS HIPOTECARIOS}

Consideremos ahora los factores que incidieron en la demanda de títulos hipotecarios. Según las cifras del RNVE, las entidades de crédito fueron las que más adquirieron estos títulos, el 75,7\% del monto total en 2007-2013 ${ }^{37}$. Los fondos de pensiones y cesantías ocuparon un lejano segundo lugar, con el 15,4\%, a lo que cabe sumar el 1,5\% de carteras colectivas. Llama la atención que, si bien la justificación de la ley de financiación hipotecaria fue corregir la brecha o descalce de plazos de los bancos comerciales hipotecarios atrayendo recursos del mercado de capitales (de inversionistas institucionales), hayan sido las entidades de crédito los principales compradores de los títulos

\footnotetext{
35 Según Cuéllar (2006), para compensar la limitación a la tasa de interés de los créditos VIS se estableció que los ingresos de estas operaciones no se gravaran durante cinco años, según el Decreto 2440 de 2005 que reglamentó los incentivos a la financiación de VIS subsidiable, establecidos en el art. 56 de la Ley 546 de 1999; pues en el cálculo del impuesto de renta se aceptó incorporar los costos y deducciones imputables a los ingresos de cartera VIS, sin las limitaciones establecidas en el Estatuto Tributario (art. 82 de la Ley 964 de 2005).

${ }^{36}$ En ese año se registró el mayor volumen de titularizaciones con 4 billones de pesos, hasta noviembre (Titularizadora, 2010).

${ }_{37}$ En tiempos normales. Para Blommestein et al. (2011), los bancos fueron compradores clave antes de la crisis mundial de 2008, porque podían distribuir el riesgo de crédito; después de la crisis tuvieron que reconstruir su capital, reducir su apalancamiento y cambiar el balance de sus activos para adecuarse a la regulación, y varios desaparecieron.
} 
hipotecarios emitidos, con adquisiciones equivalentes a las tres cuartas partes en los últimos siete años ${ }^{38}$.

Gráfica 11

Compradores titularización hipotecaria, 2007-2013

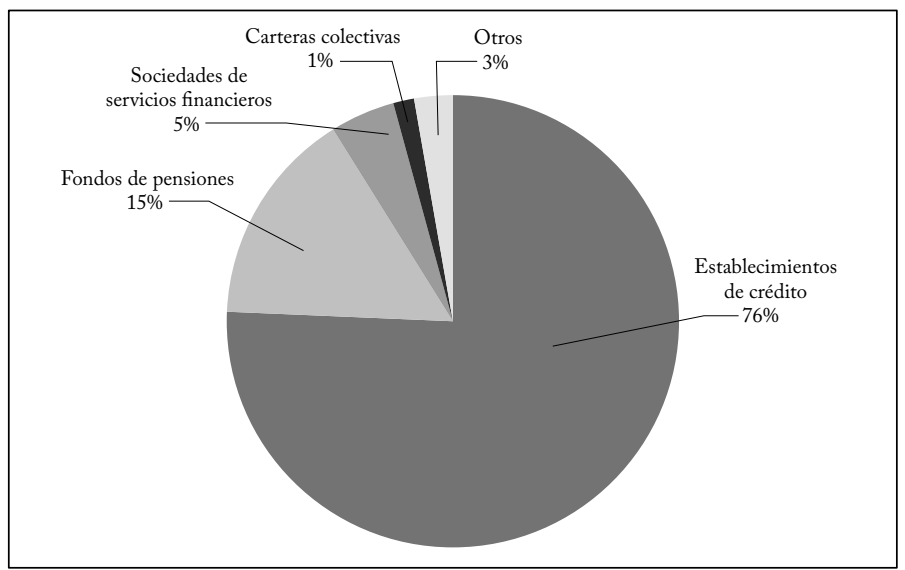

Otros incluye: personas naturales, sociedades de capitalización, fondos mutuos de inversión, fondos comunes, aseguradoras y demás personas jurídicas.

Fuente: RNVE, SFC; elaboración propia.

Este comportamiento pudo obedecer al tratamiento tributario establecido en la ley, que exoneró la rentabilidad de los títulos hipotecarios expedidos antes del 23 de diciembre de $2004^{39}$, a un plazo mayor de cinco años, prorrogado hasta $2010^{40}$. En 2005 las entidades de crédito adquirieron el 90,3\% de los títulos hipotecarios colocados en ese año; en 2010, cuando vencía el segundo plazo, sus compras llegaron al $93,3 \%{ }^{41}$. Según la Titularizadora Colombiana (2010), esta exención fue importante porque estimuló la participación en los procesos de las entidades financieras, pues los bancos preferirían incluir en sus portafolios títulos que por la exención valían más que los que no tenían ese beneficio.

38 En 2002-2005 las entidades de crédito adquirieron el 80,1\% de los títulos hipotecarios colocados, las sociedades de servicios financieros compraron el 10,6\% y los fondos de pensiones el 1,0\%. En el RNVE no hay información de colocación ni de compradores de títulos hipotecarios para el año 2006. Villar registró que entre 2002 y 2006 los bancos adquirieron el 83,3\% de los títulos emitidos y los fondos de pensiones el 3,7\% (Villar, 2006).

39 Art. 16, Ley 546 de 1999.

${ }^{40}$ El art. 81 de la Ley 964 de 2005 modificó el art. 16 de la Ley 546 de 1999, para ampliar el plazo a 11 años. Ver también el Decreto 2440 de 2005.

${ }^{41}$ En 2010 se registró el mayor saldo de cartera titularizada del periodo, como ya se señaló. 
Cabe traer a colación la motivación de tal exención tributaria. Según Cuéllar (2006), lo que la motivó fue "promover la desintermediación de la operación" para los bancos hipotecarios, mejorar temporalmente su rentabilidad y reducir los riesgos, corrigiendo así la desventaja de la financiación de compra de vivienda según lo establecido en la Ley Marco, frente a otras modalidades de financiación. Pero la exención tributaria no corrigió del todo los sesgos contra la financiación hipotecaria, y fue necesario compensarlos con bajas a largo plazo de la tasa de interés, lo que se hizo a finales de 2005 y comienzos de 2006 (ibíd.) ${ }^{42}$.

Esta argumentación es corroborada por los datos de la Titularizadora Colombiana, que muestran que la exención tributaria redujo entre 200 y 300 puntos básicos la tasa de interés de los créditos hipotecarios, y que aumentó cuando se eliminó la exención. Esto lleva a discutir la importancia de la estructura tributaria en el desarrollo de procesos que, como la titularización, se tornaron cruciales en la financiación de la economía.

Cabe preguntar por qué los fondos de pensiones y las carteras colectivas de inversión no adquirieron un mayor volumen de títulos hipotecarios si ese era el objetivo de la ley que reguló la titularización hipotecaria. Una posible respuesta es que los fondos ya estaban exentos del impuesto de renta, conforme a la Ley de Previsión Social y al Estatuto Tributario ${ }^{43}$, y que la exención no los beneficiaba realmente. Además, podían encontrarse ante una barrera a la salida del mercado, porque no se había establecido la figura del creador de mercado (market maker) para garantizar la liquidez de los títulos en el mercado secundario, lo que hacía incierta la posibilidad de liquidar los títulos antes de su vencimiento.

Por ello los inversionistas institucionales -fondos de pensiones y carteras colectivas- compraron menos del 18\% del monto emitido en títulos entre 2007 y $2013^{44}$. Pero esa proporción aumentó notablemente entre 2011 y 2013, ya agotada la exención tributaria, mientras

\footnotetext{
${ }^{42}$ En 2005 las entidades de crédito adquirieron el 90,3\% de los títulos hipotecarios colocados.

${ }^{43}$ El art. 135 de la Ley 100 de 1993 establece que los recursos de los fondos de pensiones están exentos de todo tipo de impuestos, tasas y contribuciones de cualquier origen de orden nacional, siendo aplicable a los rendimientos abonados en las cuentas individuales. E1 art. 23-2 del Estatuto Tributario establece que los fondos de pensiones no pagan impuesto de renta.

${ }^{44}$ En 2002-2005 las aseguradoras adquirieron el 2\%, los fondos de pensiones el $1 \%$ y los fondos de valores el $0,3 \%$, es decir, menos del $4 \%$. La mayor adquisición de los fondos de pensiones se registró en 2003: el 3,4\% del monto de adquisiciones de títulos hipotecarios.
} 
que los montos titularizados disminuyeron notablemente. La suma de sus compras fue superior al 52\%, y llegó al 63,4\% en 2011.

\section{CONCLUSIONES}

Recurriendo al marco de la nueva economía institucional y considerando que la titularización de activos es una innovación en la manera de financiar proyectos, el análisis de la evolución de la titularización lleva a concluir que en los años noventa hubo una relación de doble vía entre la regulación y las necesidades de la economía: en periodos normales la regulación impulsó la titularización "de caja” sobre subyacentes de diversa índole, y en el periodo de crisis la regulación dio vía libre a la canalización de recursos del mercado de capitales mediante la titularización hipotecaria a través de una sociedad titularizadora; por otro lado, la regulación respondió a realidades del mercado: en el sector inmobiliario, a la necesidad de financiar proyectos expidiendo documentos que reflejaran la rentabilidad de los proyectos de construcción; en proyectos agropecuarios, como el de levante de ganado, a la necesidad de anticipar la caja para mantener los hatos; y en la crisis del sistema UPAC, a la necesidad de resolver el descalce de plazos de los bancos hipotecarios.

En la segunda parte del periodo no se constató esa relación de doble vía, pues no hubo ningún cambio trascendental en la regulación después de 2002, cuando se reglamentó la Ley 546 de 1999. No obstante, la inflexión en el crecimiento de la titularización podría hacer pensar que hubo otra innovación en los instrumentos de financiación; pero lo que ocurrió en realidad fue que se mantuvo el predominio de los instrumentos tradicionales: bonos y títulos de deuda públicos y privados en primer lugar, y acciones y papeles comerciales en lugares secundarios.

En cuanto al cambio del marco institucional, se constató la existencia de agentes de cambio que respondieron a los incentivos de la regulación en busca de menores costos y mayor rentabilidad; de fuentes de cambio como el aprendizaje, a partir de innovaciones en otros países y de una crisis que afectó los precios relativos; de un cambio "incremental" que dio un vuelco a la regulación de la oferta pública de nuevos valores con "características y prerrogativas de los títulos valores"; y del afianzamiento de la vía del cambio mediante nuevos contratos y acuerdos que hicieron posible la titularización y que perduran hasta hoy. Pero la fuerza de la innovación desapareció a comienzos de siglo, lo que desestimuló la creación de nuevos productos financieros y condujo al mercado colombiano a ser aún más conservador. 
En lo que respecta a los factores de oferta y de demanda que incidieron en la titularización, se observó un predominio de los originadores del sector terciario, en número de procesos y en monto promedio de las titularizaciones; las de montos mayores - del sector de servicios- tuvieron un menor costo relativo de emisión. En la titularización no hipotecaria decayó en los últimos años el número y el monto de los procesos, debido a que la reducción de las tasas del crédito bancario ordinario encarece la titularización no hipotecaria como fuente de financiación. La titularización hipotecaria mostró una correlación con el comportamiento del PIB de la construcción de edificaciones entre 2003 y 2013; a comienzos de siglo se registró una alta participación de la cartera VIS titularizada; y una parte pequeña de los procesos de titularización obedeció a la necesidad de sacar la cartera hipotecaria perdida del balance de los originadores que se registró después de la crisis, mediante la retitularización.

El efecto de la tributación parece haber sido determinante en la evolución de la titularización hipotecaria, de tres maneras: 1) la exención tributaria de la rentabilidad de los títulos hipotecarios estimuló la demanda; durante su vigencia los mayores compradores fueron las entidades de crédito, y una vez terminó esta exención desapareció en gran parte el incentivo para demandar estos títulos y, por ende, para emitir títulos hipotecarios; 2) los fondos de pensiones no se vieron muy motivados a participar en la adquisición de esas titularizaciones, porque ya estaban exentos de todo tipo de impuestos; y, 3) los beneficios tributarios a la construcción de vivienda VIS incentivaron la oferta de este tipo de vivienda, y los créditos para comprarla luego fueron titularizados con garantía de Fogafín. Un efecto colateral del beneficio tributario a los títulos hipotecarios es que no se logró del todo el objetivo de la regulación; es decir, trasladar recursos de los inversionistas institucionales a la financiación de créditos hipotecarios de largo plazo.

Es necesario investigar las razones para que la innovación en la financiación de los años noventa, que marcó el comportamiento de la oferta pública, perdiera fuerza en los últimos años y la titularización dejara de ser la opción para financiar proyectos innovadores -inmobiliarios, agropecuarios y otros-, y en particular para que la capacidad transformadora de la titularización hipotecaria quedara en duda al agotarse la exención tributaria. Cabe mencionar algunos temas de estudio más específicos: las restricciones a la participación de los inversionistas institucionales, el surgimiento de otras formas de financiación fuera del mercado de valores, la percepción de un aumento 
del riesgo entre los reguladores después del 9/11, el pequeño tamaño y la poca liquidez del mercado secundario, el papel de la estructura tributaria en el desarrollo del sector.

Además, sería conveniente activar procedimientos de evaluación costo-beneficio de la regulación, revisar el marco institucional de la titularización y potenciar un instrumento que podría volver a ser útil para financiar proyectos de infraestructura, desarrollar la altillanura y cumplir las metas de construcción de vivienda programadas, que son esenciales para atender las necesidades actuales del desarrollo económico.

\section{REFERENCIAS BIBLIOGRÁFICAS}

1. Arias, L. "Securitization: aspectos introductorios del proceso de titularización en el derecho inglés", Revista de Derecho Privado 26, 2014, pp. 385-403.

2. Baldwin, R. M. Understanding regulation: Theory, strategy and practice, Oxford, Oxford University Press, 2012.

3. Bathelt, H. y J. Glücker. "Institutional change in economic geography", Progress in human geography 38, 3, 2014, pp. 340-363.

4. Blanco, C. "La titularización en Colombia: diez años de desarrollo", Contexto 18, 2004, pp. 7-38.

5. Blanco, C. "Impacto de la regulación en el comportamiento de la oferta pública de valores en Colombia", Contexto 26, 2008. pp. 9-41.

6. Blanco, C. Diez años de la Ley 546 de 1999 de financiación hipotecaria, Colección de Derecho y Economía, vol. 7, Bogotá, Universidad Externado de Colombia, 2010, pp. 13-74.

7. Blommestein, H. K. "Outlook for the securitization market", OECD Journal: Financial Markets Trend 1, 2011 [http://eds.a.ebscohost.com/ eds/pdfviewer/].

8. Brownlow, G. "Structure and change: Douglass North's economics", Journal of Economic Methodology 17, 3, 2010, pp. 301-316.

9. Cuéllar, M. M. ¿̇A la vivienda quién la ronda? Situación y perspectivas de la politica de vivienda en Colombia, vol. I, Bogotá, Universidad Externado de Colombia, 2006.

10. Cuevas, H. Fundamentos de la economía de mercado, Bogotá, Universidad Externado de Colombia, 2001.

11. Díaz, J. U. "Teoría económica institucional y creación de empresas", Investigaciones Europeas de Dirección y Economía de la Empresa 11, 3, 2005, pp. 209-230.

12. Dolfsma, W. y R. Verburg. "Structure, agency and the role of values in processes institutional change", Journal of Economic Issues XLII, 4, 2008, pp. 1031-1054.

13. Frunză, R. y M. Stranciu. "The institutional change and its implications on economic development", Romanian Economic and Bussines Review 2, 1, s. f., pp. 71-78.

14. Heinrich, T. y H. Schwardt. "Institutional inertia and institutional change in an expanding normal-form game", Games 4, 3, 2013, pp. 398-425. 
15. Kaniadakis, A. y P. Constantinides. "Innovating financial information infrastructures: The transition of legacy assets to the securitization market", Journal of the Association for Information Systems 15, 5, 2014, pp. 244-262.

16. Kerle, P. y L. Gullifer. "The future of trade receivables securitization in Europe”, Journal of Structures Finance 19, 1, 2013, pp. 71-76.

17. López, F. y F. García Q. "Institutional approaches to economic development: The current status of the debate", Journal of Economic Issues XLVI, 4, 2012, pp. 921-940.

18. Manrique, C. E. Introducción a la titularización. Aspectos jurídicos, Bogotá, Asociación Bancaria, 1994.

19. Marin, K. et al. "The Volker rule and conflict-of-interest rulemaking: Will traditional securitization survive?", Journal of Structured Finance 18, 1, 2012, pp. 20-21.

20. MHCP. "Informe final", Misión de Estudios del Mercado de Capitales, Bogotá, Fedesarrollo, 1996.

21. Morales, C. "La racionalidad jurídica en crisis: Pierre Bourdieu y Gunther Teubner (estudio preliminar)”, P. Bourdieu y G. Teubner, La fuerza del derecho, Bogotá, Uniandes-Instituto Pensar-Siglo del Hombre, 2005, pp. 13-80.

22. Müller, J. “An other path: Local systems of innovation in the South", Forum for Development Studies 40, 2, 2013, pp. 235-260.

23. North, D. Instituciones, cambio institucional y desempeño económico, México, D.F., Fondo de Cultura Económica, 1993.

24. Pigou, A. C. La economía del bienestar, Madrid, Aguilar, 1946.

25. Pinzón, M. Aproximaciones al análisis económico del Derecho, Bogotá, Universidad Externado de Colombia, 2010.

26. Podolski, E. "Regulating synthetic securitisation following the global financial crisis", Australian Economic Review 45, 1, 2012, pp. 14-28.

27. Rubio, M. Economía jurídica. Introducción al análisis económico del derecho iberoamericano, Bogotá, Universidad Externado de Colombia, 2007.

28. Taylor, L. et al. "Securitization of brands names: Basic concepts and its use in practice", Journal of Brand Management 17, 1, 2009, pp. 62-83.

29. Titularizadora Colombiana. "Diez años de titularización hipotecaria en Colombia”, Segundo Foro de Vivienda. Una tarea de todos, un techo para todos, Bogotá, 2010.

30. Uhde, A.; C. Farruggio y T. Michalak. "Wealth effects of credit risk securitization in European banking", Journal of Business Finance $\xi^{\circ}$ Accounting 39, 1, pp. 193-228.

31. Villar, L. El crédito hipotecario en Colombia, condiciones para su ampliación, Bogotá, ICAV-Universidad Externado de Colombia, 2006. 